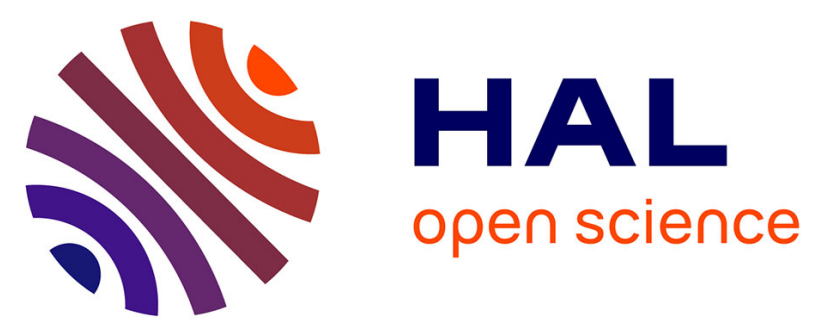

\title{
Escherichia coli Rho GTPase-activating toxin CNF1 mediates NLRP3 inflammasome activation via p21-activated kinases-1/2 during bacteraemia in mice
}

Océane Dufies, Anne Doye, Johan Courjon, Cédric Torre, Gregory Michel, Celine Loubatier, Arnaud Jacquel, Paul Chaintreuil, Alissa Majoor, Rodolphe r. Guinamard, et al.

\section{To cite this version:}

Océane Dufies, Anne Doye, Johan Courjon, Cédric Torre, Gregory Michel, et al.. Escherichia coli Rho GTPase-activating toxin CNF1 mediates NLRP3 inflammasome activation via p21-activated kinases$1 / 2$ during bacteraemia in mice. Nature Microbiology, 2021, 6 (3), pp.401 - 412. 10.1038/s41564-02000832-5 . hal-03473187

\author{
HAL Id: hal-03473187 \\ https://hal.science/hal-03473187
}

Submitted on 9 Dec 2021

HAL is a multi-disciplinary open access archive for the deposit and dissemination of scientific research documents, whether they are published or not. The documents may come from teaching and research institutions in France or abroad, or from public or private research centers.
L'archive ouverte pluridisciplinaire HAL, est destinée au dépôt et à la diffusion de documents scientifiques de niveau recherche, publiés ou non, émanant des établissements d'enseignement et de recherche français ou étrangers, des laboratoires publics ou privés. 


\title{
Escherichia coli Rho GTPase-activating toxin CNF1 mediates NLRP3 inflammasome activation via p21-activated kinases-1/2 during bacteraemia in mice
}

\author{
Océane Dufies ${ }^{1}$, Anne Doye ${ }^{1}$, Johan Courjon ${ }^{1,2}$, Cédric Torre', Gregory Michel', Celine Loubatier1, \\ Arnaud Jacquel (1D), Paul Chaintreuil', Alissa Majoor', Rodolphe R. Guinamard', Alexandre Gallerand', \\ Pedro H. V. Saavedra ${ }^{3}$, Els Verhoeyen ${ }^{1,4}$, Amaury Rey ${ }^{4}{ }^{4}$, Sandrine Marchetti ${ }^{1}$, Raymond Ruimy ${ }^{1,2}$, \\ Dorota Czerucka, ${ }^{5,6}$, Mohamed Lamkanfi ${ }^{3}{ }^{3}$, Bénédicte F. Py ${ }^{4}$, Patrick Munro ${ }^{1}$, Orane Visvikis ${ }^{1}$ and \\ Laurent Boyer (1) 1,6凶
}

\begin{abstract}
Inflammasomes are signalling platforms that are assembled in response to infection or sterile inflammation by cytosolic pattern recognition receptors. The consequent inflammasome-triggered caspase-1 activation is critical for the host defence against pathogens. During infection, NLRP3, which is a pattern recognition receptor that is also known as cryopyrin, triggers the assembly of the inflammasome-activating caspase-1 through the recruitment of ASC and Nek7. The activation of the NLRP3 inflammasome is tightly controlled both transcriptionally and post-translationally. Despite the importance of the NLRP3 inflammasome regulation in autoinflammatory and infectious diseases, little is known about the mechanism controlling the activation of NLRP3 and the upstream signalling that regulates the NLRP3 inflammasome assembly. We have previously shown that the Rho-GTPase-activating toxin from Escherichia coli cytotoxic necrotizing factor-1 (CNF1) activates caspase-1, but the upstream mechanism is unclear. Here, we provide evidence of the role of the NLRP3 inflammasome in sensing the activity of bacterial toxins and virulence factors that activate host Rho GTPases. We demonstrate that this activation relies on the monitoring of the toxin's activity on the Rho GTPase Rac2. We also show that the NLRP3 inflammasome is activated by a signalling cascade that involves the p21-activated kinases 1 and 2 (Pak1/2) and the Pak1-mediated phosphorylation of Thr 659 of NLRP3, which is necessary for the NLRP3-Nek7 interaction, inflammasome activation and IL-1 1 cytokine maturation. Furthermore, inhibition of the Pak-NLRP3 axis decreases the bacterial clearance of CNF1-expressing UTI89 E. coli during bacteraemia in mice. Taken together, our results establish that Pak1 and Pak2 are critical regulators of the NLRP3 inflammasome and reveal the role of the Pak-NLRP3 signalling axis in vivo during bacteraemia in mice.
\end{abstract}

U ropathogenic E. coli is the leading causative agent of bacteraemia ${ }^{1}$. It is therefore fundamental to decipher the mechanisms that determine the fate of this pathogen in the blood. The innate immune sensing of $E$. coli is mediated by pattern recognition receptors (PRRs), mainly by Toll-like receptor-4 (TLR4), which detects bacterial lipopolysaccharides (LPS). LPS are the principal component of the external membrane of both pathogenic and non-pathogenic E. coli and, therefore, pattern-triggered immunity does not seem to be sufficient to gauge the pathogenic potential of microorganisms. As TLR4 is activated by both live and dead bacteria, pattern-triggered immunity is certainly important for monitoring the quantity of bacteria, but is not sufficient to determine their quality $^{2}$. One strategy to determine microbial pathogenicity is the detection of virulence factor activities that are specific to pathogens ${ }^{3}$. Virulence factors of uropathogenic E. coli include CNF1, which is a Rho-GTPase-targeting toxin. The CNF1 toxin bears enzymatic activity that is responsible for the post-translational deamidation of a specific glutamine residue on a subset of Rho GTPases, namely $\mathrm{Rac}, \mathrm{Cdc} 42$ and $\mathrm{RhoA}^{4-6}$. This modification destroys the intrinsic and GTPase-activating-protein- (GAP)-regulated ability of these Rho GTPases to hydrolyse GTP, conferring dominant positive mutant characteristics to Rho proteins ${ }^{4-6}$. This modification increases GTP-bound activated Rho proteins and the activation of their downstream signalling pathways ${ }^{6}$. By modulating the host cytoskeleton, these virulence factors confer to bacteria invasion properties and the ability to modulate inflammatory responses ${ }^{7-10}$. Among the virulence factors, there are more than 30 that target Rho GTPases. They are either activators or inhibitors of Rho GTPases, both of which activate caspase-1 (refs. ${ }^{11,12}$ ).

Inflammasomes are signalling platforms that are assembled by cytosolic PRRs that activate caspase-1. NLRP3 oligomerizes on infection or cellular damage, and recruits ASC, Nek7 and caspase-1 to form the NLRP3 inflammasome. This assembly results in ASC speck formation, cleavage of pro-caspase- 1 into active caspase- 1 and

'Université Côte d'Azur, Inserm, C3M, Nice, France. ${ }^{2}$ Université Côte d'Azur, CHU Nice, Nice, France. ${ }^{3}$ Department of Internal Medicine and Pediatrics, Ghent University, Ghent, Belgium. ${ }^{4} \mathrm{CIRI}$, Centre International de Recherche en Infectiologie, Université de Lyon, Inserm U1111, Université Claude Bernard Lyon 1, CNRS UMR5308, ENS de Lyon, Lyon, France. ${ }^{5}$ Centre Scientifique de Monaco, Monaco, Monaco. ${ }^{6}$ LIA ROPSE, Laboratoire International Associé Université Côte d'Azur, Centre Scientifique de Monaco, Nice, France. e-mail: laurent.boyer@univ-cotedazur.fr 
the maturation of pro-IL- $1 \beta$ into IL- $1 \beta$. The NLRP3 inflammasome assembly is controlled by both the priming by TLR ligands and activation signals. Furthermore, the NLRP3 inflammasome assembly is regulated by phosphorylation and ubiquitination events ${ }^{13,14}$. Despite a variety of identified NLRP3 activators, the upstream signalling pathways that control NLRP3 post-translational modifications and activation mechanisms remain unclear ${ }^{14}$. Interestingly, toxins that inactivate Rho GTPases activate the Pyrin inflammasome through the modification of its phosphorylation status by the PKN1/2 kinases. The Pyrin inflammasome has been shown to detect toxins that inhibit Rho GTPases, but information about the sensing of toxins that activate Rho GTPases through inflammasomes is lacking $^{15,16}$. In this Article, we used the CNF1 toxin as a model of the Rho-GTPase-activating virulence factor to demonstrate the role of the Pak-NLRP3 axis in sensing CNF1 activity and controlling the clearance of bacteria during bacteraemia.

\section{Results}

CNF1-triggered immunity requires NLRP3. We set up an assay to monitor the CNF1-triggered activation of caspase-1 using a FAM-YVAD-FMK (FAM-FLICA) probe. Primary bone-marrow-derived macrophages (BMDMs) isolated from $\mathrm{BALB} / \mathrm{c}$ mice were treated with CNF1 and analysed using confocal microscopy. Cells with dots of FAM-FLICA staining corresponding to ASC specks were counted (Extended Data Fig. 1a). This unbiased screen revealed that NLRP3 is the major NLR involved in CNF1-triggered caspase-1 activation (Fig. 1a). The role of NLRP3 in this pathway was confirmed in BMDMs isolated from C57BL/6 mice bearing ASC-citrine knockin using flow cytometry (Extended Data Fig. 1b,c). In this assay, we quantified the percentage of cells with ASC specks as previously described ${ }^{17,18}$. These data revealed the conserved role of NLRP3 in the response to CNF1 in macrophages isolated from both $\mathrm{BALB} / \mathrm{c}$ and $\mathrm{C} 57 \mathrm{BL} / 6 \mathrm{~J}$ background.

Next, we investigated the role of NLRP3 in CNF1-triggered immunity. Co-treatment of BMDMs isolated from wild-type (WT) mice with the CNF1 toxin together with the NLRP3 inhibitor MCC950 was sufficient to block caspase-1 activity, demonstrating that the CNF1 toxin is an NLRP3 activator (Fig. 1b,c). Importantly, the number of FAM-FLICA ${ }^{+}$cells was substantially reduced in BMDMs that were treated with catalytically inactive mutant $\mathrm{CNF}^{\mathrm{C} 866 \mathrm{~S}}$. This result provided evidence that CNF1 toxin activity is monitored by NLRP3, rather than the pattern of the toxin ${ }^{3}$. Furthermore, CNF1-triggered maturation and secretion of IL- $1 \beta$ and activation of caspase- 1 was impaired in NLRP3-knockout BMDMs (Fig. 1d and Supplementary Fig. 1). By contrast, CNF1 treatment did not affect the secretion of IL- 6 or TNF- $\alpha$, two cytokines that are not regulated by inflammasomes (Fig. 1d and Supplementary Fig. 1). Activation of the NLRP3 inflammasome is often associated with pyroptosis ${ }^{19}$. To investigate whether CNF1 triggered pyroptosis, we measured propidium iodide incorporation (Extended Data Fig. 2a), lactate dehydrogenase (LDH) release (Extended Data Fig. 2b) and gasdermin D (GSDMD) cleavage (Extended Data Fig. 2c). In contrast to nigericin, we did not observe any of these pyroptosis markers after CNF1 treatment and we observed a similar level of CNF1-triggered caspase-1 activation and IL- $1 \beta$ maturation/secretion in WT and GSDMD-knockout macrophages (Extended Data Fig. 2d,e). We subsequently tested the role of the NLRP3 inflammasome regulator Nek7 in CNF1-triggered immunity. Transfection of Nlrp3 or Nek7 short interfering RNA (siRNA) in BMDMs inhibited CNF1-triggered IL-1 $\beta$ maturation (Extended Data Fig. 3a,b). $\mathrm{K}^{+}$efflux is an upstream event for NLRP3 inflammasome activation and Nek7 requires $\mathrm{K}^{+}$efflux for NLRP3 inflammasome assembly ${ }^{14,20}$. We observed that $\mathrm{KCl}$ treatment was sufficient to inhibit CNF1-triggered caspase-1 cleavage (Extended Data Fig. 3c). Importantly, we confirmed that the $\mathrm{KCl}$ treatment did not inhibit CNF1 toxin activity towards Rho GTPase activation using a glutathione S-transferase (GST)-Pak-Rac-binding domain
(RBD) pull-down assay (Extended Data Fig. 3d). We next investigated whether other toxins that target Rho GTPases have the ability to activate the NLRP3 inflammasome. Dermonecrotic toxin (DNT) from Bordetella has transglutaminase activity towards Rho GTPases that enables the constitutive activation of Rho GTPases ${ }^{6,10}$. We observed that purified recombinant DNT triggered the activation of caspase-1 in WT macrophages, but not in NLRP3-knockout macrophages (Extended Data Fig. 4a). We next tested whether the NLRP3 activation was triggered specifically by virulence factors activating Rho GTPases using NLRP3 inflammasome reconstitution in HEK293T cells ${ }^{21}$. Cells were transfected with plasmids encoding the DNT toxin or the injected bacterial virulence factors YopE from Yersinia containing a GAP domain that enables inactivation of the Rho GTPases ${ }^{6}$. We observed NLRP3-dependent IL-1 $\beta$ maturation when cells were transfected with the Rho-GTPase-activating toxin DNT, but not when cells were transfected with the Rho GTPase inhibitor YopE (Extended Data Fig. 4b). The expression of the virulence factor SopE from Salmonella containing a guanine nucleotide exchange factor (GEF) domain activating Rac and Cdc42 (refs. ${ }^{6,22}$ ) or the expression of the GEF domain of the $\mathrm{Dbl}$ exchange factor $\left(\mathrm{Dbl}^{495-826}\right)^{23}$ were sufficient to trigger NLRP3-dependent IL-1 $\beta$ maturation (Extended Data Fig. 4b,c). Taken together, we showed that the activation of Rho GTPases by toxins and virulence factors triggered the activation of the NLRP3 inflammasome and that Rac has a major role in this pathway.

Activation of the NLRP3 inflammasome by CNF1 relies on Rac2 and the Pak serine-threonine kinases. Although the CNF1 toxin is a Rho GTPases activator and Rac2 is a haematopoietic-specific Rho GTPase that is involved in the innate immune response to the $\mathrm{CNF} 1$ toxin $^{24}$, the contribution of Racl and Rac2 in this process is still unknown. To investigate the role of Rac in the CNF1-triggered NLRP3 inflammasome activation, we knocked down Rac1 and/ or Rac2 using siRNA in BMDMs. Interestingly, Rac1 knockdown resulted in an increase in the level of CNF1-triggered IL-1 $\beta$ maturation whereas Rac2 knockdown was sufficient to block it (Fig. 2a). We tested whether activated GTP-bound Rac2 levels would increase when Racl was targeted by siRNA. The GST-Pak-RBD pull-down analysis showed an increase in activated Rac2 when Rac1 was knocked-down using siRNA (Fig. 2b). These data demonstrate the critical role of Rac2 in CNF1-triggered IL- $1 \beta$ maturation (Fig. 2a,b). To determine the molecular mechanism of the caspase-1 activation, we used a system of NLRP3 inflammasome reconstitution in HEK293T cells. This analysis showed that CNF1 is sufficient for the NLRP3 inflammasome activation-triggered caspase-1 cleavage and that the co-treatment of CNF1 with MCC950 inhibited this caspase-1 activation (Fig. 2c). The transfection of Rac2 GTPase or activated mutant forms of Rac2 (including Q61E mimicking the CNF1 modification or Q61L and G12V) were sufficient to activate caspase-1, in contrast to the inactive mutant Rac2 ${ }^{\mathrm{T} 17 \mathrm{~N}}$ (Fig. 2d). Interestingly, the strength of caspase- 1 activation observed using the activated forms of Rac2 GTPase was correlated with the amount of Rho GTPases that were bound to GST-Pak-RBD (Fig. 2e). These data indicate that NLRP3 senses the activation level of the Rho GTPase Rac2 proportionally to the strength of activation rather than by detecting the structural modification made by the toxin as it would be predicted for a classical PRR.

The correlation between caspase- 1 activation and the amount of Rac2 bound to GST-Pak-RBD suggested a potential role of Pak kinases in CNF1-triggered NLRP3 inflammasome activation. We therefore knocked-down Pak1 and/or Pak2 in BMDMs by transfecting siRNA (Pak3 is predominantly expressed in the brain ${ }^{25,26}$ ). We observed a major decrease in caspase-1 cleavage in cells treated with Pak1 siRNA but a moderate impact when using siRNA targeting Pak2, indicating that Pak1 has a main role (Fig. 3a). However, we could not exclude the possibility that the total inhibition of 


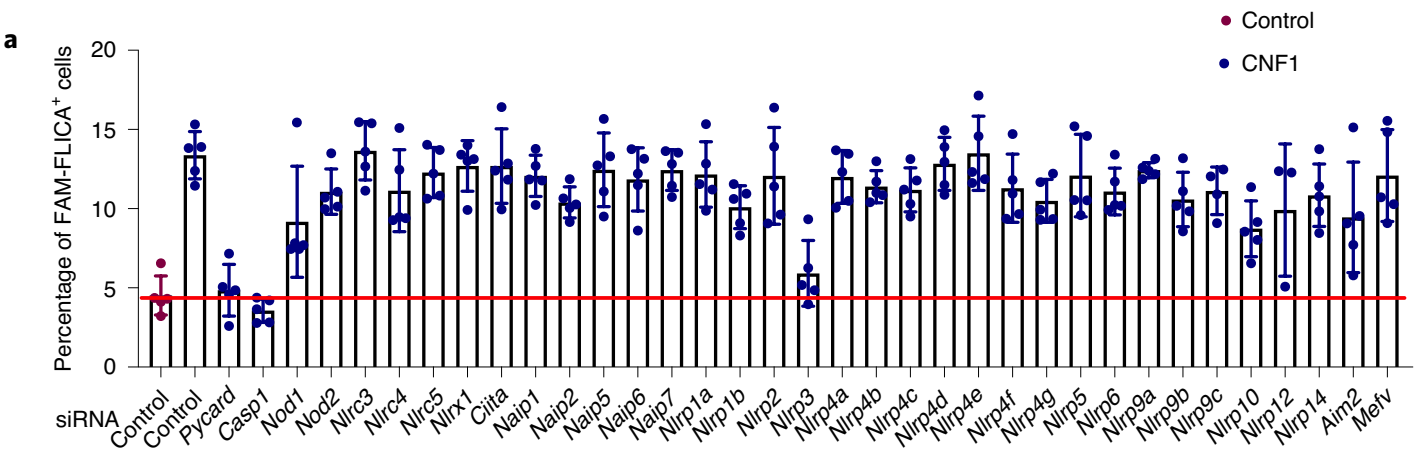

b NLRP3 KO

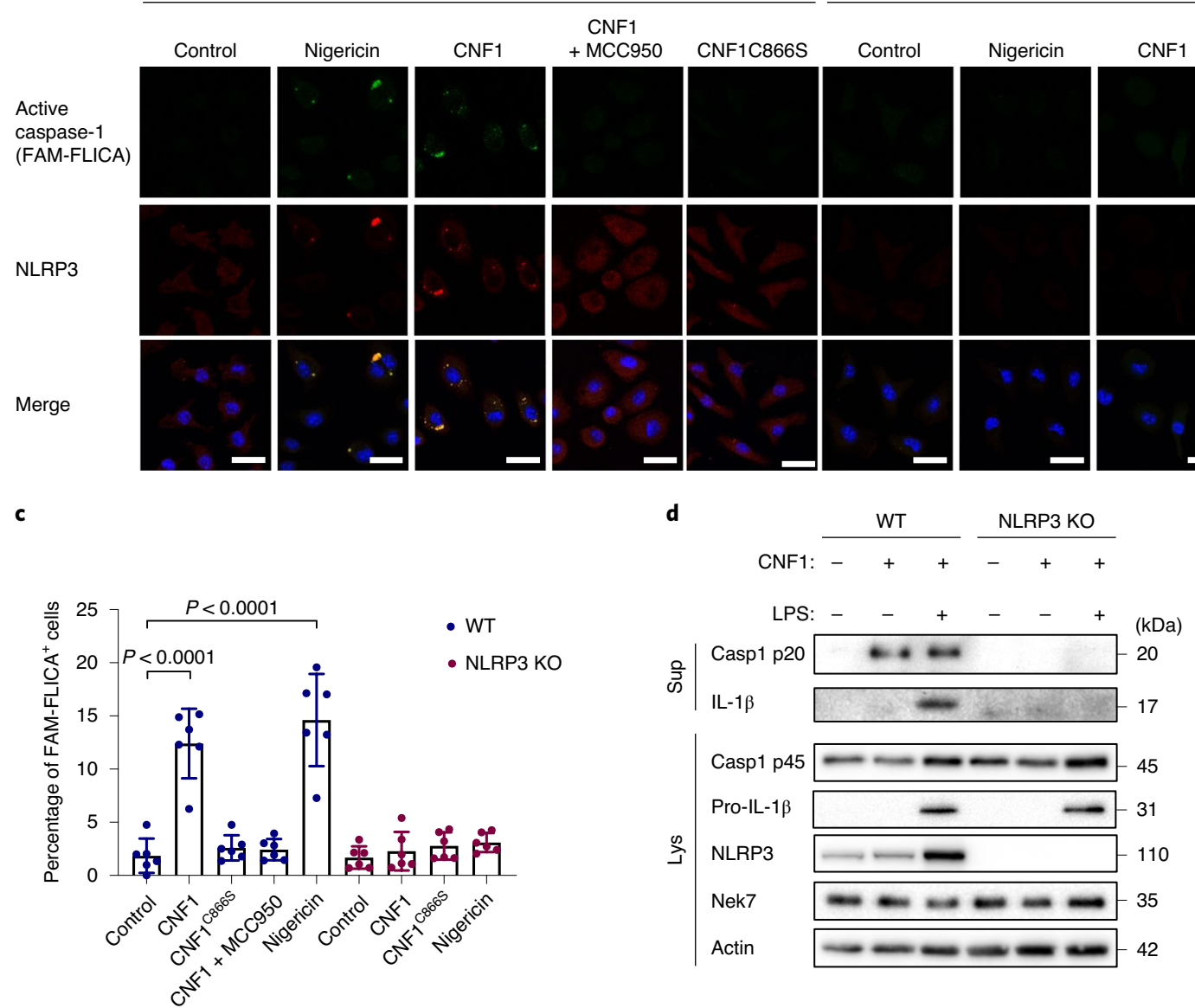

Fig. 1 | CNF1-triggered caspase-1 activation and IL-1 $\beta$ maturation requires NLRP3. $\mathbf{a}$, BMDMs isolated from BALB/c mice were transfected with the indicated siRNA for $72 \mathrm{~h}$ before treatment for $6 \mathrm{~h}$ with CNF1 $\left(500 \mathrm{ng} \mathrm{ml}^{-1}\right)$. Active caspase-1 was detected using the FAM-FLICA probe. Cells harbouring FAM-FLICA dots were counted as positive using Fiji. The red horizontal line indicates the mean percentage of FAM-FLICA ${ }^{+}$cells in the untreated control. Each dot represents 200 cells. $n=1,800$ cells. Data are mean \pm s.e.m. b,c, BMDMs extracted from WT or NLRP3-knockout C57BL/6J mice were or were not pretreated for $45 \mathrm{~min}$ with MCC950 $(1 \mu \mathrm{M})$ before treatment for $6 \mathrm{~h}$ with CNF1 $\left(500 \mathrm{ng} \mathrm{ml}^{-1}\right)$, or the CNF1 catalytic inactive mutant CNF1 ${ }^{\text {C866s }}$ $\left(500 \mathrm{ng} \mathrm{ml}^{-1}\right)$ or nigericin $(5 \mu \mathrm{M})$. b. Cells were analysed using immunofluorescence and confocal imaging. Active caspase-1 (FAM-FLICA) is shown in green, NLRP3 in red and nuclei in blue. Scale bars, $20 \mu \mathrm{m}$. c, Quantification of FAM-FLICA+ cells in WT (blue) or NLRP3-knockout BMDMs (red). Each dot represents 100 cells. $n=600$ cells. Data are mean \pm s.e.m. Statistical analyses were performed using two-tailed unpaired Student's $t$-tests. d, WT or NLRP3-knockout BMDMs were treated with CNF1 $\left(500 \mathrm{ng} \mathrm{ml}^{-1}\right)$ and/or LPS (100 $\left.\mathrm{ng} \mathrm{ml}^{-1}\right)$ for $8 \mathrm{~h}$ before the supernatants (Sup) and cell lysates (Lys) were collected and analysed using immunoblotting. Experiments were repeated at least three times, and representative data are shown.

caspase- 1 cleavage observed with the Pak1 siRNA treatment might be due to a limit in the detection level of cleaved caspase-1, or to Pak1 siRNA that may affect Pak2, suggesting that there is a partial Pak1/2 redundancy. The treatment with Pak1 inhibitors (IPA-3 or FRAX597) was sufficient to block the CNF1-triggered IL-1 $\beta$ maturation that was observed in macrophages treated with LPS, and was also sufficient to block caspase-1 activation (Fig. 3b,c). The inhibition of the caspase- 1 cleavage after IPA- 3 treatment was similarly observed in macrophages treated with DNT (Extended Data Fig. 4d). Interestingly, IPA-3 was shown to inhibit the binding of activated forms of Rac and Cdc42 to Pak1, thereby inhibiting the autophosphorylation of Thr 423, whereas the FRAX597 


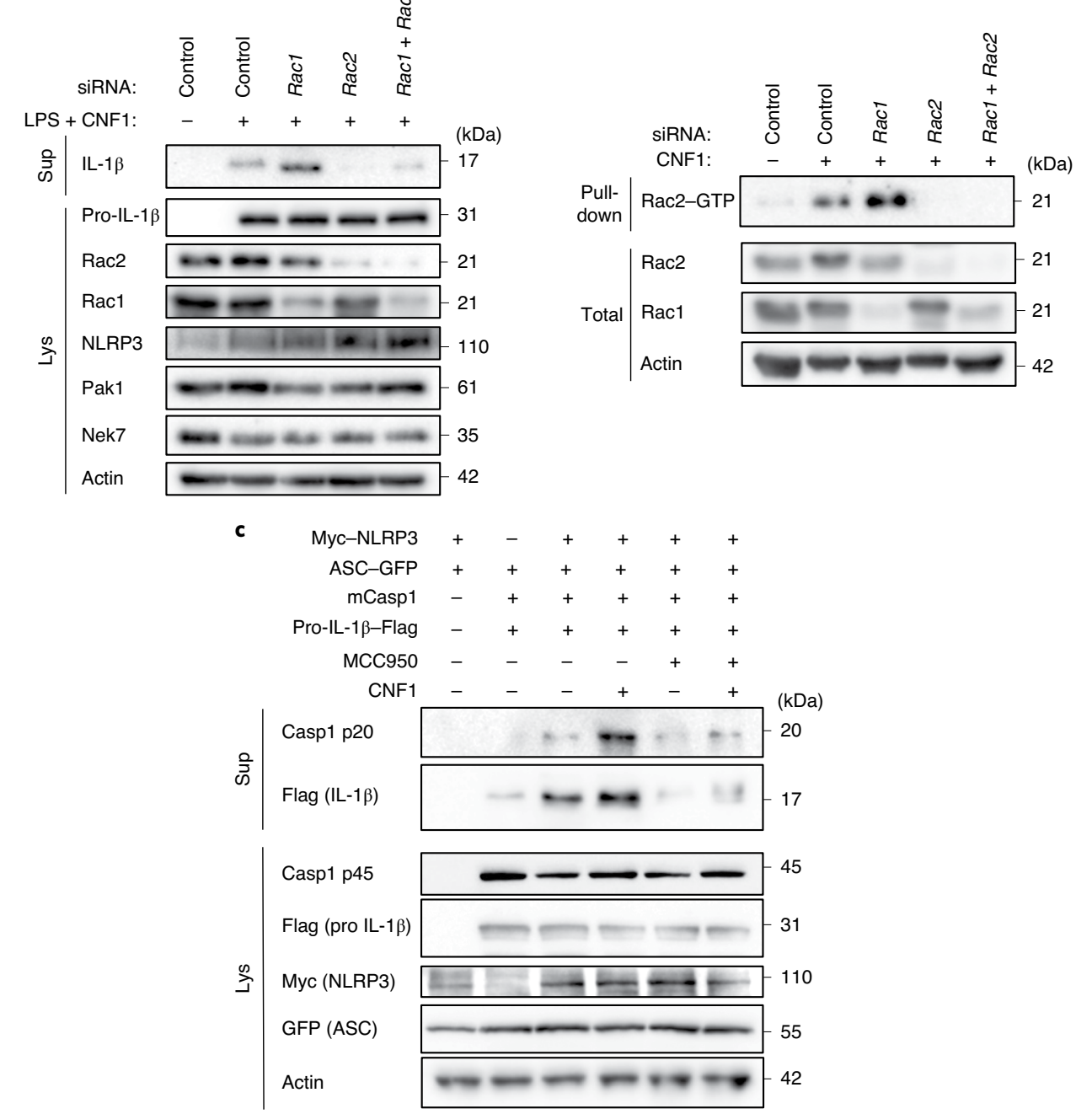

\section{d}

$\mathrm{Myc}-\mathrm{NLRP} 3+++++$

$\mathrm{ASC}-\mathrm{GFP}+++++$

$\mathrm{mCasp} 1+++++$

\begin{tabular}{l|l|l} 
HA-Rac2 - WT Q61E Q61L G12V T17N & (kDa) \\
ڤे|Casp1 p20 &
\end{tabular}

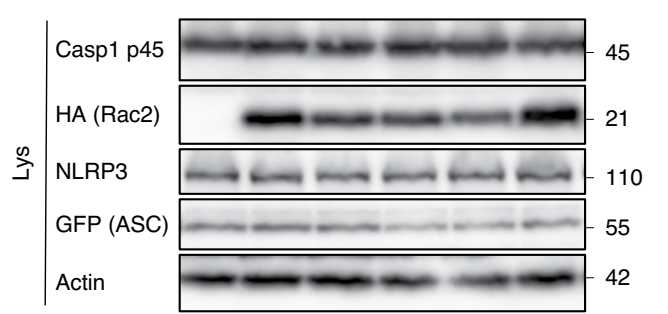

e

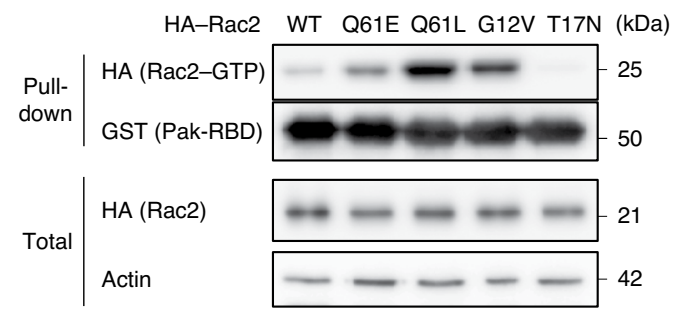

Fig. 2 | Rac2 activation triggers NLRP3 inflammasome activation. a, BMDMs extracted from BALB/c mice were transfected with siRNA targeting the indicated isoform of Rac GTPase for $72 \mathrm{~h}$ and treated with CNF1 $\left(500 \mathrm{ng} \mathrm{ml}^{-1}\right)$ and LPS $\left(100 \mathrm{ng} \mathrm{ml}^{-1}\right)$ for $8 \mathrm{~h}$. Supernatants and cell lysates were analysed using immunoblotting. b, Immortalized BMDMs (iBMDMs) were transfected with the indicated siRNA for $72 \mathrm{~h}$ before being treated or not treated with CNF1 ( $500 \mathrm{ng} \mathrm{ml}^{-1}$ ) for $6 \mathrm{~h}$ before analysis using a GST-Pak-RBD pull-down assay. The Rac2 associated with the GST-Pak-RBD beads is indicated as Rac2-GTP. c,d, HEK293T cells were transfected for $16 \mathrm{~h}$ with plasmids encoding NLRP3 inflammasome components: Myc-NLRP3, green fluorescent protein (GFP)-tagged ASC, mouse caspase-1 (mCasp1) and pro-IL-1 $1 \beta$-Flag as indicated, before analysing caspase-1 cleavage or pro-IL-1 $1 \beta$ maturation using immunoblotting. c, Cells were pretreated or not with $1 \mu \mathrm{M}$ MCC950 for $45 \mathrm{~min}$ before treatment for $6 \mathrm{~h}$ with CNF1 $\left(500 \mathrm{ng} \mathrm{ml}^{-1}\right)$. d, Cells were transfected with the following haemagglutinin (HA)-tagged mutants of Rac2: the constitutively active mutant mimicking CNF1-induced deamidation Rac2 ${ }^{\text {Q61E }}$ (Q61E), the constitutively active mutants Rac2 ${ }^{\mathrm{Q} 61 \mathrm{~L}}$ (Q61L) or Rac2 ${ }^{\mathrm{G} 12 \mathrm{~V}}$ (G12V), or the dominant negative mutant Rac2 ${ }^{\mathrm{T} 17 \mathrm{~N}}$ (T17N). Supernatants and cell lysates were analysed using immunoblotting. e, HEK293T cells were transfected for $16 \mathrm{~h}$ with HA-tagged active mutants Rac2 ${ }^{\mathrm{Q61E}}$, Rac2 ${ }^{\mathrm{Q} 61 \mathrm{~L}}$ or Rac2 ${ }^{\mathrm{G} 12 \mathrm{~V}}$, or the dominant negative mutant Rac2 ${ }^{T 17 N}$ before analysis using a GST-Pak-RBD pull-down assay. HA-Rac2 associated with the GST-Pak-RBD beads is indicated as Rac2GTP. Experiments were repeated at least three times, and representative data are shown. 


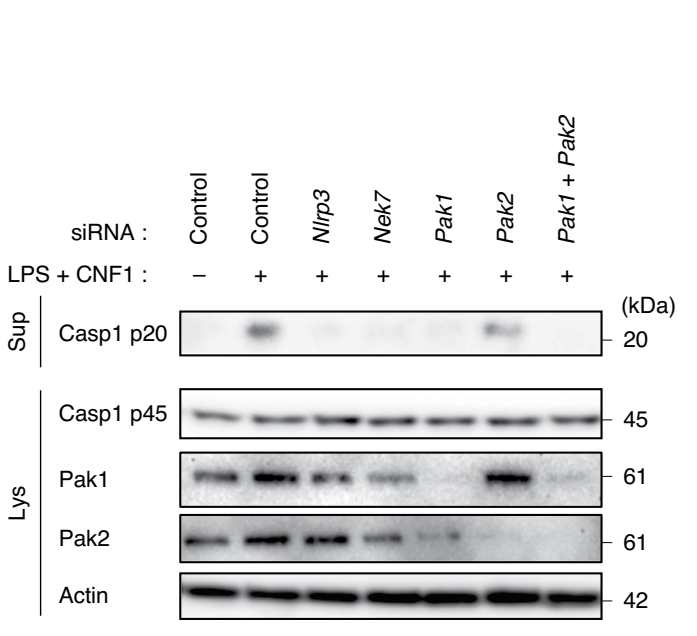

b

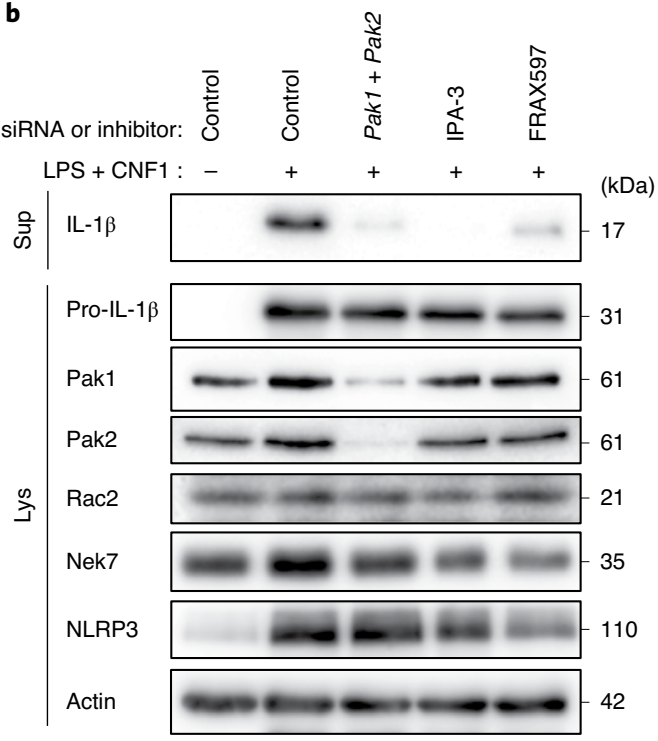

e

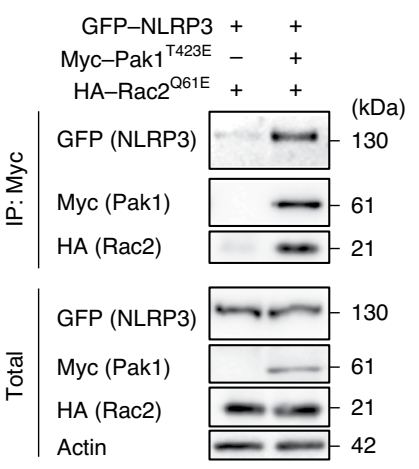

f

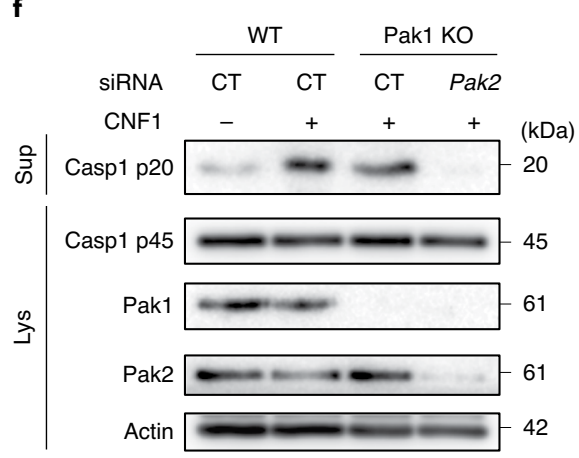

d

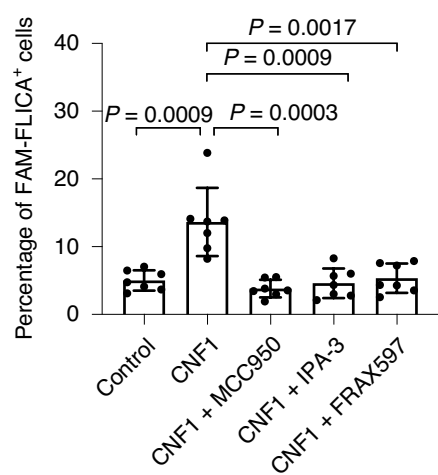

今े|

$\mid \begin{array}{lll}\text { Flag (pro-IL-1 } \beta \text { ) } & \\ \text { NLRP3 } & & \\ & & \\ \text { GFP (ASC) } & \\ \text { Myc (Pak1) } & & \\ \text { Casp1 p45 } & & \\ \text { Actin } & & \\ & & \end{array}$

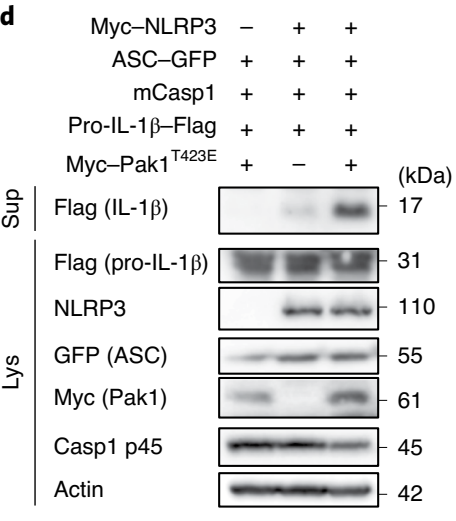

g

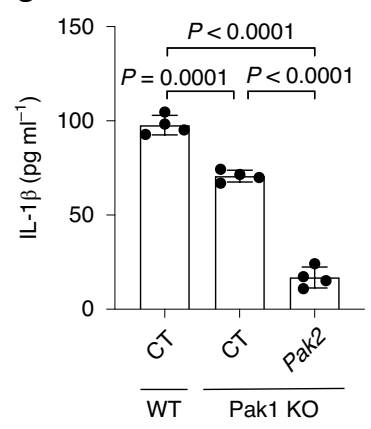

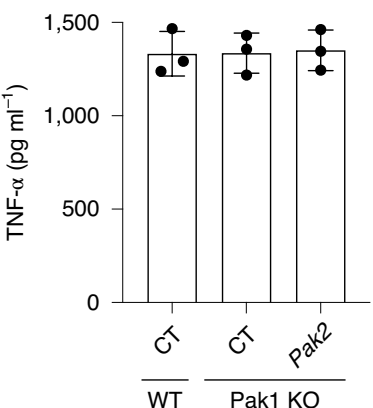

Fig. 3 | Rac2-NLRP3 signalling is dependent on Pak1 kinase. a, BMDMs isolated from BALB/c mice were transfected for $72 \mathrm{~h}$ with siRNA targeting Nlrp3, Nek7, Pak1 or Pak2 as indicated; non-targeting siRNA was used as a control. Cells were treated with CNF1 $\left(500 \mathrm{ng} \mathrm{ml}^{-1}\right)$ and LPS $\left(100 \mathrm{ng} \mathrm{ml}^{-1}\right)$ for $8 \mathrm{~h}$, as indicated. Supernatants and cell lysates were analysed using immunoblotting. b, BMDMs isolated from BALB/c mice were transfected with Pak1-and Pak2-targeting siRNA or with non-targeting siRNA for $72 \mathrm{~h}$, and treated with $5 \mu \mathrm{M} \mathrm{IPA}-3,1 \mu \mathrm{M}$ FRAX597 or vehicle for 45 min before treatment with $\mathrm{CNF1}\left(500 \mathrm{ng} \mathrm{ml}^{-1}\right.$ ) and LPS $\left(100 \mathrm{ng} \mathrm{ml}^{-1}\right)$ for $8 \mathrm{~h}$. Supernatants and cell lysates were analysed using immunoblotting. c, BMDMs isolated from BALB/c mice were treated with vehicle (control), or treated either with $1 \mu \mathrm{M} \mathrm{MCC} 950,5 \mu \mathrm{M}$ IPA-3 or $1 \mu \mathrm{M}$ FRAX597 for $45 \mathrm{~min}$ before treatment with CNF1 ( $500 \mathrm{ng} \mathrm{ml}^{-1}$ ) for $6 \mathrm{~h}$. Active caspase-1 was stained with FAM-FLICA, analysed using microscopy and FAM-FLICA+ cells were counted. Each dot represents 100 cells. $n=800$ cells. Data are mean \pm s.e.m. Statistical analyses were performed using two-tailed unpaired Student's $t$-tests. d, HEK293T cells were transfected as indicated with plasmids encoding components of the NLRP3 inflammasome (Myc-NLRP3, ASC-GFP, mouse caspase-1) and pro-IL-1 $\beta$-Flag together with Myc-Pak17423E, and pro-IL-1 $\beta$ Flag cleavage was analysed using immunoblotting. e, HEK293T cells were transfected with plasmids encoding GFP-NLRP3, Myc-Pak1 ${ }^{\text {T423E }}$ and HA-Rac2 ${ }^{\mathrm{Q61E}}$. Cell lysates were processed for anti-Myc immunoprecipitation (IP). f, BMDMs isolated from WT or Pak1-knockout C57BL/6J mice were transfected 72 h with non-targeting or Pak2-targeting siRNA before treatment with CNF1 $\left(500 \mathrm{ng} \mathrm{ml}^{-1}\right)$ for $8 \mathrm{~h}$. Supernatants and cell lysates were analysed using immunoblotting. CT, control. $\mathbf{g}$, BMDMs isolated from WT or Pak1-knockout C57BL/6J mice were transfected for $72 \mathrm{~h}$ with non-targeting or Pak2-targeting siRNA before treatment with CNF1 $\left(500 \mathrm{ng} \mathrm{ml}^{-1}\right)$ and LPS $\left(100 \mathrm{ng} \mathrm{ml}^{-1}\right)$ for $8 \mathrm{~h}$. Supernatants were analysed using enzyme-linked immunosorbent assay (ELISA) for IL-1 $\beta$ ( $n=4$ biologically independent samples) and TNF- $\alpha(n=3$ biologically independent samples). Data are mean \pm s.e.m. Statistical analyses were performed using two-tailed unpaired Student's $t$-tests. Experiments were repeated at least three times, and representative data are shown. 
is an ATP-competitive inhibitor ${ }^{27}$. In the inflammasome reconstitution system in HEK293T, we expressed the activated form of Pak1 (T423E) together with caspase-1, ASC and pro-IL-1 $\beta$, and we observed no IL-1 $\beta$ maturation. By contrast, when NLRP3 was transfected together with ASC and caspase-1, the expression of the activated form of Pak1 was sufficient to trigger maturation of IL- $1 \beta$ (Fig. 3d). Furthermore, phosphorylated forms of Pak colocalized in dot-like structures with NLRP 3 and active caspase-1 (Supplementary Fig. 2). We next investigated whether Rac2, Pak1 and NLRP3 proteins formed a complex. We found NLRP3 interacting with activated Rac2 when activated Pak1 was expressed (Fig. 3e). We next investigated whether Pak1 was involved in the nigericin-triggered activation of the NLRP3 inflammasome and observed that IPA-3 treatment was sufficient to inhibit both caspase-1 cleavage and the release of LDH (Extended Data Fig. 5a,b). Furthermore, siRNA targeting of Pak1 was found to decrease nigericin-triggered caspase-1 maturation (Extended Data Fig. 5c).

To genetically prove the involvement of Pak1 in NLRP3 inflammasome activation, we used Pak1-knockout mice. We observed a reduction in caspase-1 cleavage triggered by CNF1 in Pak1-knockout macrophages and a reduction in IL-1 $\beta$ secretion (Fig. 3f,g). By contrast, the secretion of TNF- $\alpha$ was unaffected (Fig. $3 g$ ). Both caspase- 1 cleavage and IL- $1 \beta$ secretion triggered by CNF1 were substantially reduced when the Pak1-knockout macrophages were treated with the Pak2 siRNA, suggesting that there is a partial compensation in Pak1-knockout macrophages (Fig. 3f,g).

Pak1 phosphorylates NLRP3 and triggers inflammasome activation. To further investigate whether NLRP3 is a substrate for the Pak1 serine-threonine kinase, we set-up an in vitro kinase assay. When both Pak1 and NLRP3 proteins were incubated with ATP ${ }^{32 \mathrm{P}}$, we observed a band at the size of NLRP3, indicating that NLRP3 is directly phosphorylated by Pak1 in vitro (Fig. 4a). The in vitro kinase assay was then used to identify the phosphorylated sites of NLRP3 by analysing the band corresponding to NLRP3 using mass spectrometry. The analysis revealed that Pak1 phosphorylates NLRP3 at three independent positions that correspond to Ser 163, Ser 198 and Thr 659 in the human NLRP3 (Extended Data Fig. 6a,c and Supplementary Table 1). Interestingly, the Ser 163 and Ser 198 residues were previously reported to be phosphorylated, and Ser 198 was reported to be important for NLRP3 priming ${ }^{28}$. NLRP3 Thr 659 was not reported to be phosphorylated and, interestingly, the identified peptide appears to be conserved between humans and mice (Extended Data Fig. 6d). Reinforcing the potential conservation of the Pak-NLRP3 axis, CNF1-triggered caspase-1 activation was observed in primary human macrophages and was inhibited by treatment with NLRP3 inhibitor or Pak1 inhibitor (Extended Data Fig. 7a,b). In the inflammasome reconstitution system, we next expressed the activated Pak1 $1^{\mathrm{T} 423 \mathrm{E}}$ and compared the effect of the expression of NLRP3 WT with the triple-mutant NLRP3 $3^{\text {S163A } 198 \mathrm{AT} 659 \mathrm{~A}}$ or single mutants NLRP3 ${ }^{\mathrm{S163A}}, \mathrm{NLRP}^{\mathrm{S} 198 \mathrm{~A}}$ and
NLRP3 ${ }^{\mathrm{T} 659 \mathrm{~A}}$ in which the phosphorylated residues were replaced with alanine residues, which are not sensitive to phosphorylation. The results show that the triple-mutant NLRP3 ${ }^{\text {S163A S198A T659A }}$ and the single mutant NLRP3 ${ }^{\mathrm{T} 659 \mathrm{~A}}$ is impaired in IL- $1 \beta$ maturation triggered by the activated $\mathrm{Pak1}^{\mathrm{T} 423 \mathrm{E}}$, indicating that the NLRP3 Thr 659 residue has an important role in Pak1-triggered NLRP3 inflammasome activation (Fig. 4b). Furthermore, we generated a T659D phosphomimetic NLRP3 mutant and observed that, compared with NLRP3 ${ }^{\mathrm{T} 659 \mathrm{~A}}$, the NLRP3 ${ }^{\mathrm{T} 659 \mathrm{D}}$ mutant had an increased ability to trigger pro-IL- $1 \beta$ maturation (Fig. $4 \mathrm{c}$ ). Importantly, similar results were obtained when the Rho-GTPase-activating virulence factor SopE was transfected to activate the pathway, highlighting the involvement of this NLRP3 post-translational regulation for the sensing of other virulence factors activating Rho GTPases (Extended Data Fig. 8a). We next stably reconstituted immortalized macrophages knocked-out for NLRP3 with plasmids encoding either NLRP3 or NLRP3 ${ }^{\text {T659A }}$. Confirming our results, we observed impaired CNF1-triggered IL-1 $\beta$ maturation/secretion in macrophages expressing NLRP3 ${ }^{\mathrm{T} 659 \mathrm{~A}}$ compared with macrophages expressing WT NLRP3 (Fig. 4d,e). By contrast, TNF- $\alpha$ was similarly secreted by macrophages expressing either NLRP3 or NLRP3 ${ }^{\mathrm{T} 659 \mathrm{~A}}$ (Fig. 4e). After treatment with the DNT toxin, we also observed an impairment in CNF1-triggered IL- $1 \beta$ maturation in macrophages expressing the NLRP ${ }^{\mathrm{T} 659 \mathrm{~A}}$ mutant compared with macrophages expressing WT NLRP3 (Extended Data Fig. 8b). Reinforcing the importance of this NLRP3 phosphorylation site in the inflammasome activation process, nigericin-triggered IL- $1 \beta$ maturation and secretion were reduced in macrophages expressing the NLRP3 ${ }^{\mathrm{T} 659 \mathrm{~A}}$ compared with the macrophages expressing NLRP3, whereas TNF- $\alpha$ secretion was unaffected (Extended Data Fig. 9). Taken together, these results show that phosphorylation of NLRP3 at Thr 659 has a functional role, and that Pak1 is a regulator of the NLRP3 inflammasome. Structural analysis of the NLRP3-Nek7 interaction revealed a putative interaction domain at the level of the Thr 659 of NLRP3 (ref. ${ }^{29}$ ). Using co-immunoprecipitation experiments, we tested whether the NLRP3 ${ }^{\text {S163A S198A T659A }}$ triple mutant or NLRP3 ${ }^{\text {S163A }}$, NLRP3 ${ }^{\text {S198A }}$ and NLRP ${ }^{\text {T659A }}$ single mutants affected the interaction with endogenous Nek7. The interaction between NLRP3 and Nek7 was impaired in the NLRP3 $3^{\text {S163A } 198 \mathrm{~A} \text { T659A }}$ triple mutant and in the NLRP3 ${ }^{\mathrm{T} 659 \mathrm{~A}}$ mutant, indicating that Thr 659 is a critical site for NLRP3-Nek7 interaction and suggesting that the phosphorylation of NLRP3 at Thr 659 is important for the NLRP3-Nek7 interaction (Fig. 4f). This observation was confirmed using anti-Nek7 immunoprecipitation in macrophages in which we found a decrease in NLRP3 ${ }^{\mathrm{T} 659 \mathrm{~A}}$ binding to Nek7 compared with WT NLRP3 (Fig. 4g).

Clearance of CNF1-expressing $E$. coli during bacteraemia requires the Pak-NLRP3 signalling axis. We next addressed the relevance of the CNF1-triggered Pak-NLRP3 signalling axis during infection. We observed an increase in caspase-1 maturation when macrophages were infected with CNF1-expressing E. coli compared

Fig. 4 | Pak1 phosphorylates NLRP3 to promote inflammasome activation. a, In vitro [ $\gamma$-32P]ATP kinase assay using human recombinant NLRP3 (arrows) and human recombinant Pak1 (arrowheads) analysed using autoradiography and Coomassie brilliant blue (CBB) staining. b, HEK293T cells were transfected with plasmids encoding components of the NLRP3 inflammasome (ASC-GFP, mouse caspase-1), pro-IL-1 $\beta-F l a g, M y c-P a k 1^{\top 423 E}$, with Myc-NLRP3, Myc-NLRP3 ${ }^{\text {S163A }}$, Myc-NLRP3 ${ }^{\text {S198A }}$, Myc-NLRP3 ${ }^{\text {T659A }}$ or Myc-NLRP3 ${ }^{\text {S163AS198A T659A }}$, and IL-1 $\beta$ maturation was analysed using immunoblotting. c, HEK293T cells were transfected with plasmids encoding components of the NLRP3 inflammasome (ASC-GFP, mouse caspase-1) and Myc-Pak1 ${ }^{\text {T423E, }}$ with Myc-NLRP3, Myc-NLRP3 ${ }^{\text {T659A }}$ or Myc-NLRP3 ${ }^{\text {T659D }}$, and IL-1 $\beta$ maturation was analysed using immunoblotting. $\mathbf{d}, \mathbf{e}$, NLRP3-knockout iBMDMs that were reconstituted with either NLRP3 or NLRP3 ${ }^{\text {T659A }}$ were treated with vehicle or LPS (100 ng ml ${ }^{-1}$ ) and CNF1 (500 ng ml ${ }^{-1}$ ) for 8 h. d, Supernatants and cell lysates were analysed using immunoblotting. e, Supernatants were analysed using ELISA for IL-1 $\beta$ ( $n=4$ biologically independent samples) and TNF- $\alpha$ ( $n=3$ biologically independent samples). Data are mean \pm s.e.m. Statistical analyses were performed using two-tailed unpaired Student's $t$-tests. f, HEK293T cells were transfected with plasmids encoding Myc-NLRP3, Myc-NLRP3 ${ }^{\text {S163A }}$, Myc-NLRP3 ${ }^{\text {S198A }}$, Myc-NLRP3 ${ }^{\text {T659A }}$ or Myc-NLRP3 ${ }^{\text {S163AS198A T659A }}$. Cell lysates were processed for anti-Myc immunoprecipitation and endogenous Nek7 was revealed using anti-Nek7 antibodies. g, NLRP3-knockout iBMDMs that were reconstituted with either NLRP3 or NLRP3 ${ }^{\text {T659A }}$ were treated with CNF1 ( 500 ng ml $^{-1}$ ) for 6 h. Cell lysates were analysed using immunoprecipitation with anti-Nek7 antibodies or isotypic IgG. Experiments were repeated at least three times, and representative data are shown. 
with the isogenic E. coli CNF1-knockout strain, and treatment with NLRP3 or Pak1 inhibitors decreased the caspase-1 cleavage triggered by the E. coli expressing CNF1 (Fig. 5a). Furthermore, IL-1 $\beta$ secretion triggered by the CNF1-expressing E. coli was reduced when bacteria were added to NLRP3-knockout macrophages (Fig. 5b). Furthermore, the secretion of IL- $1 \beta$ triggered by CNF1-expressing E. coli in macrophages complemented with the NLRP3 $3^{\mathrm{T} 659 \mathrm{~A}}$ mutant was decreased compared with control macrophages expressing
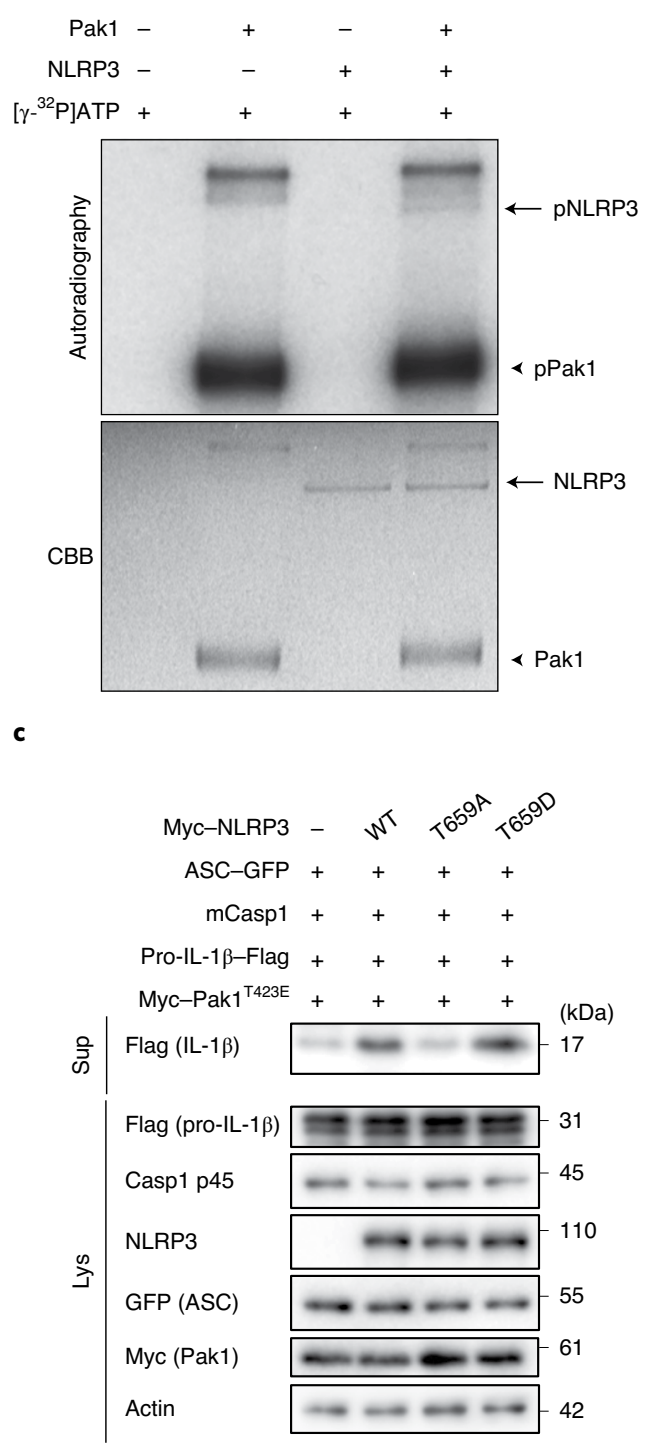

b

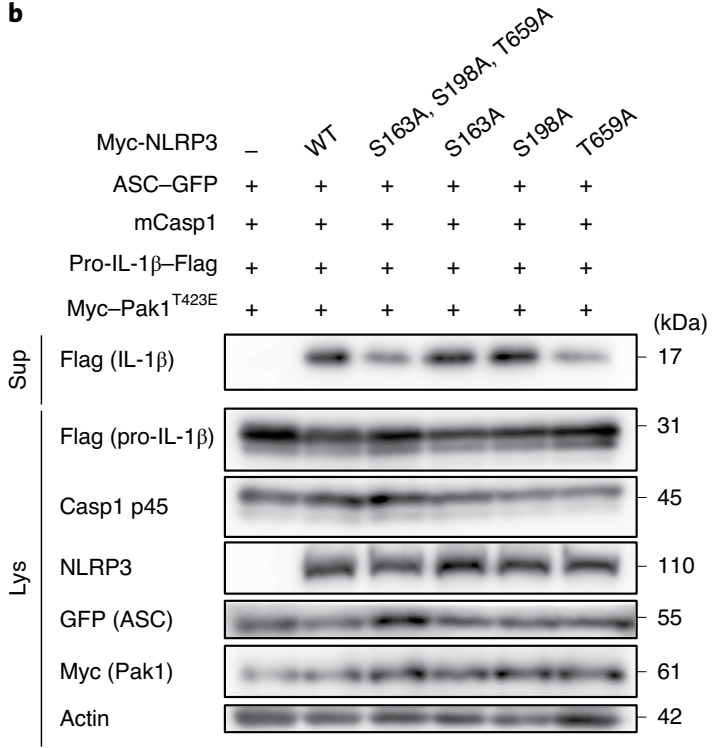

d
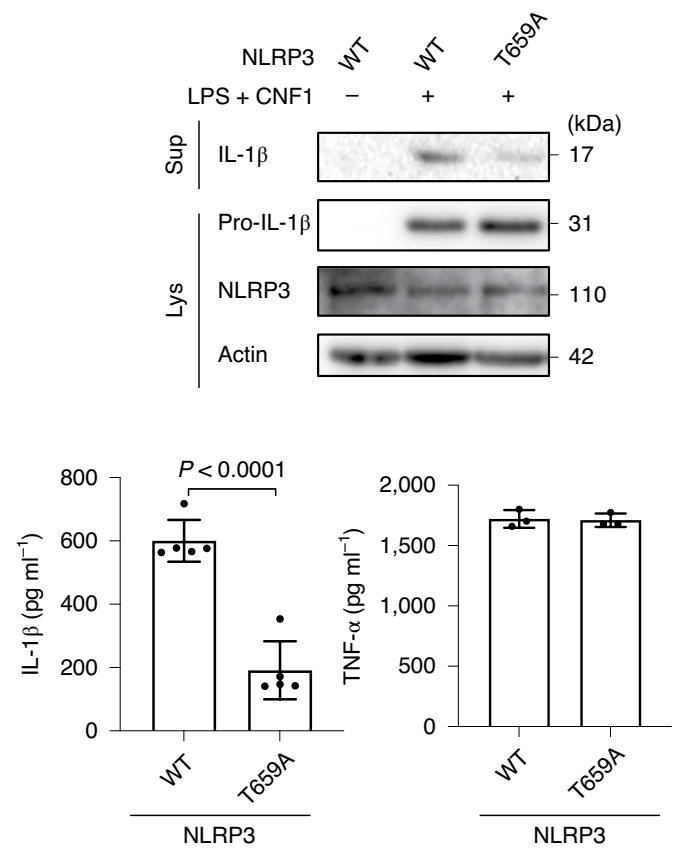

g

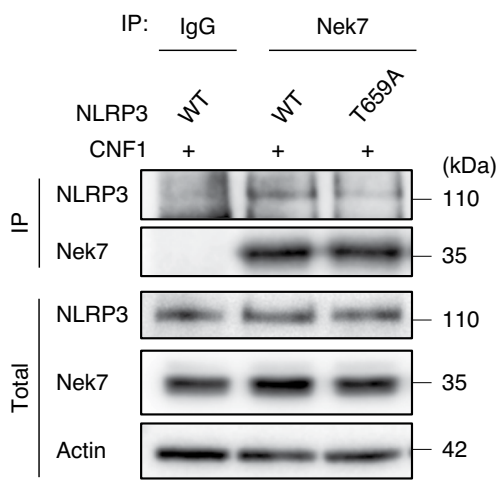


NLRP3 (Fig. 5c). TNF- $\alpha$ secretion measured during infection with CNF1-expressing E. coli was not affected in macrophages that were isolated from NLRP3-knockout mice or macrophages expressing the NLRP3 ${ }^{\text {T659A }}$ mutant (Fig. 5b,c). We previously demonstrated that the CNF1 toxin expressed by E. coli triggered both an immune response in vivo and bacterial clearance during bacteraemia ${ }^{11}$. To investigate the role of Pak1 during CNF1-expressing E. coli bacteraemia, we used the Pak1 inhibitor AZ13711265, which blocks CNF1-triggered IL-1 $\beta$ maturation (Supplementary Fig. 3) and is associated with good in vivo pharmacokinetic properties ${ }^{27}$. We monitored the bacterial burden during bacteraemia in control mice or mice injected with AZ13711265. Mice bacteraemia was measured for each mouse at $4 \mathrm{~h}, 24 \mathrm{~h}$ and $48 \mathrm{~h}$ after infection (Fig. $5 \mathrm{~d}$ ). The bacterial clearance of CNF1-expressing E. coli was observed; no bacteria were detectable at $48 \mathrm{~h}$ in all of the control animals (Fig. 5d). We measured a statistically significant higher bacterial load at $48 \mathrm{~h}$ and $77 \%$ of the animals were found to be positive for bacteraemia in the mice that were injected with the Pak1 inhibitor, indicating that in vivo the inhibition of Pak1 is sufficient to inhibit the CNF1-expressing E. coli clearance (Fig. 5d). We next used an NLRP3 inhibitor, MCC950, which has been shown to be efficient in vivo ${ }^{30}$. We monitored bacteraemia in mice injected with MCC950 compared with the controls. The bacterial clearance of CNF1-expressing E. coli in mice injected with the NLRP3 inhibitor was significantly higher at $48 \mathrm{~h}$, and $70 \%$ of the animals were found to be positive for bacteraemia (Fig. 5d). Consistent with our model, we observed no significant effect of both AZ13711265 and MCC950 towards the bacterial clearance when we infected mice with the isogenic E. coli CNF1-knockout strain (Extended Data Fig. 10a). To genetically prove this point, we infected WT mice, NLRP3-knockout mice or Pak1-knockout mice, and compared the CNF1-expressing E. coli burden. Consistent with the results obtained with the NLRP3 and Pak1 inhibitors, we did not detect any bacteria in the blood of infected WT mice at $48 \mathrm{~h}$, whereas we measured a mean of $1.5 \times 10^{4}$ and $2.5 \times 10^{2}$ bacteria per mouse in the blood of NLRP3-knockout and Pak1-knockout mice, respectively (Fig. 5e,f). The smaller effect observed in Pak1-knockout mice compared with NLRP3-knockout mice could be explained by the redundancy observed between Pak1 and Pak2 at the cellular level. The difference in the clearance of CNF1-expressing $E$. coli measured at $48 \mathrm{~h}$ between WT and NLRP3-knockout mice was still observable at later time points and was not observed when mice were infected with the isogenic $E$. coli CNF1-knockout strain, indicating the specificity of the CNF1 response towards the NLRP3 pathway in vivo (Extended Data Fig. 10b,c). Furthermore, we measured a similar trend in the clearance of the CNF1-expressing E. coli strain in WT and GSDMD-knockout mice (Extended Data Fig. 10d). We next monitored the bacterial burden in mice that were infected with CNF1-expressing E. coli and treated with AZ13711265, MCC950 or both. We observed no differences in the bacterial clearance between the three groups (Fig. 5d). NLRP3-knockout mice that were injected with vehicle or with AZ13711265 demonstrated no differences in bacterial clearance, suggesting that Pak1 and NLRP3 act within the same signalling pathway during bacteraemia (Fig. $5 \mathrm{~g}$ ). Together, these results unravel the critical role of Pak1 and NLRP3 in the clearance of CNF1-expressing bacteria and their importance in the innate immune response during bacteraemia.

\section{Discussion}

Our results shed light on a regulatory mechanism for NLRP3 after the activation of Rac2 by the bacterial toxin CNF1. The level of NLRP3 inflammasome activation is correlated with the strength of the interaction between activated Rac2 and Pak1-RBD, indicating that the innate immune system can adapt its response to the level of Rac2 activity. This seems to be an elegant strategy to deliver a commensurate response to the level of CNF1 toxin activity. Notably, the phosphorylated peptide containing Thr 659 of human NLRP3 isolated by mass spectrometry is highly conserved between species, and the Pak-NLRP3 axis is conserved in human macrophages and is involved in the nigericin-triggered NLRP3 inflammasome activation. Complementary studies will be necessary to determine the precise molecular mechanism in other species or in other contexts as well as to determine whether the phosphorylation of NLRP3 at Thr 659 is a consensus site used by other kinases. Nevertheless, our results show that phosphorylation of NLRP3 at Thr 659 is important for NLRP3 inflammasome activation and suggest that it is implicated in NLRP3-related inflammatory disorders or susceptibility to infection.

Our results suggest that there is redundancy between Pak1 and Pak2, as shown by a partial compensation by Pak2 in Pak1-knockout macrophages and mice. Further studies are required to clarify the importance of each of the group-1 Pak proteins in the activation of the NLRP3 inflammasome. Unfortunately, the Pak2-knockout mutations in mice are embryonically lethal (at embryonic day 8.0) and these studies would require the generation of conditional transgenic mice ${ }^{31}$.

We unravelled a CNF1-triggered secretion of IL-1 $\beta$ that is not linked to an increase in cell death and is independent of GSDMD. Studies of NLRP3 inflammasome canonical triggers have demonstrated different IL- $1 \beta$ secretion scenarios. In the conventional scenario, caspase- 1 cleaves the inflammasome-related cytokines and GSDMD to generate active N-GSDMD ${ }^{32,33}$. N-GSDMD relocates in the plasma membrane to form pores, enabling IL- $1 \beta$ secretion $^{32,33}$. GSDMD pores are associated with pyroptosis in the case of classical inflammasome activation or are controlled during inflammasome hyperactivation, leading to secretion without pyroptosis ${ }^{34-36}$. The CNF1-triggered IL- $1 \beta$ secretion seems to fall into another category, independent of both GSDMD cleavage and cell death, that may share similarities with the unconventional IL- $1 \beta$ secretion $^{37}$. This unconventional secretion relies on the affinity of IL- $1 \beta$ to the plasma membrane ruffles that are characteristic of the CNF1-triggered Rac GTPase activation. The mechanism explaining how CNF1 triggered caspase- 1 activation without GSDMD cleavage remains to be elucidated and may be unique to toxins activating Rho GTPases. One hypothesis is that the activation of Rac2, in parallel to the

Fig. 5 | Pak1 and NLRP3 control the burden of CNF1-expressing E. coli during bacteraemia. a, BMDMs isolated from C57BL/6 mice were pretreated for

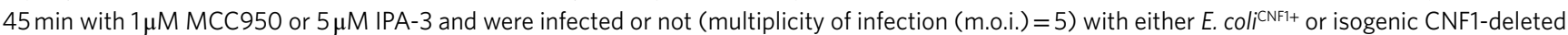
mutant $E$. colicNF1-. Supernatants and cell lysates were analysed using immunoblotting. b,c, BMDMs isolated from C57BL/6 or C57BL/6 NLRP3-knockout mice $(\mathbf{b})$ or iBMDMs expressing NLRP3 or NLRP3 ${ }^{\text {T659A }}(\mathbf{c})$ were infected $(m .0 . i .=5)$ with $E$. colicNF1+. The supernatants were analysed using ELISA. $n=4$ biologically independent samples per group. Data are mean \pm s.e.m. Statistical analyses were performed using two-tailed unpaired Student's $t$-tests. d-g, Mice were intravenously infected with $10^{7}$ colony-forming units (c.f.u.) of E. colicNF1+, before collecting peripheral blood at $4 \mathrm{~h}, 24 \mathrm{~h}$ and $48 \mathrm{~h}$ for the measurement of bacteraemia. d, C57BL/6J mice were injected intraperitoneally with vehicle, or with $50 \mathrm{mg} \mathrm{kg}^{-1} \mathrm{MCC} 550(n=10 \mathrm{mice}), 10 \mathrm{mg} \mathrm{kg}{ }^{-1}$ AZ13711265 ( $n=10$ mice) or both once a day $\left(n=9\right.$ mice). ${ }^{\star \star} P<0.01$ (each individual inhibitor-treated group compared with the group injected with vehicle). e, WT ( $n=7$ mice) or NLRP3-knockout C57BL/6J mice ( $n=6$ mice) were analysed. ${ }^{\star \star \star} P<0.001 . \mathbf{f}, \mathrm{WT}$ ( $n=4$ mice) or Pak1-knockout C57BL/6J mice were analysed ( $n=4$ mice). ${ }^{\star} P<0.05$. g, NLRP3-knockout C57BL/6J mice were injected intraperitoneally with $10 \mathrm{mg} \mathrm{kg}^{-1} \mathrm{AZ13711265}(n=7 \mathrm{mice})$ or vehicle ( $n=9$ mice) once each day. Experiments were repeated at least two times, and representative data are shown. Data are the geometric mean $\pm 95 \%$ confidence interval. Statistical analyses were performed using two-tailed nonparametric Mann-Whitney U-tests. ${ }^{\star} P<0.05,{ }^{\star \star} P<0.01,{ }^{\star \star \star} P<0.001$. 
Pak1-NLRP3 pathway activation, inhibits the cleavage of GSDMD. Similar to Toxoplasma gondii, the NF- $\mathrm{KB}$ activation triggered by Rac2 might be another mechanism explaining the IL- $1 \beta$ secretion independent of cell death and GSDMD ${ }^{38}$. Rac2 signalling may also regulate a potassium channel explaining the inhibition by $\mathrm{KCl}$ of the CNF1-triggered IL- $1 \beta$ secretion. Favouring this hypothesis, Rac GTPases have been found to modulate Kir2.1, a Kir-family potassium channel ${ }^{39}$.
Our study shows that NLRP3 is a major sensor of toxins that activate Rho GTPases, whereas previous research has shown the sensing of Rho-GTPase-inactivating toxins by Pyrin ${ }^{12}$. These studies highlight that the mammalian innate immune system has evolved strategies that share similarities with the effector-triggered immunity to detect abnormal activation of Rho GTPases ${ }^{3,40,41}$. Interestingly, both inactivation of RhoA and activation of Rac2 by bacterial toxins are monitored by Pyrin and NLRP3, respectively. More precisely, b
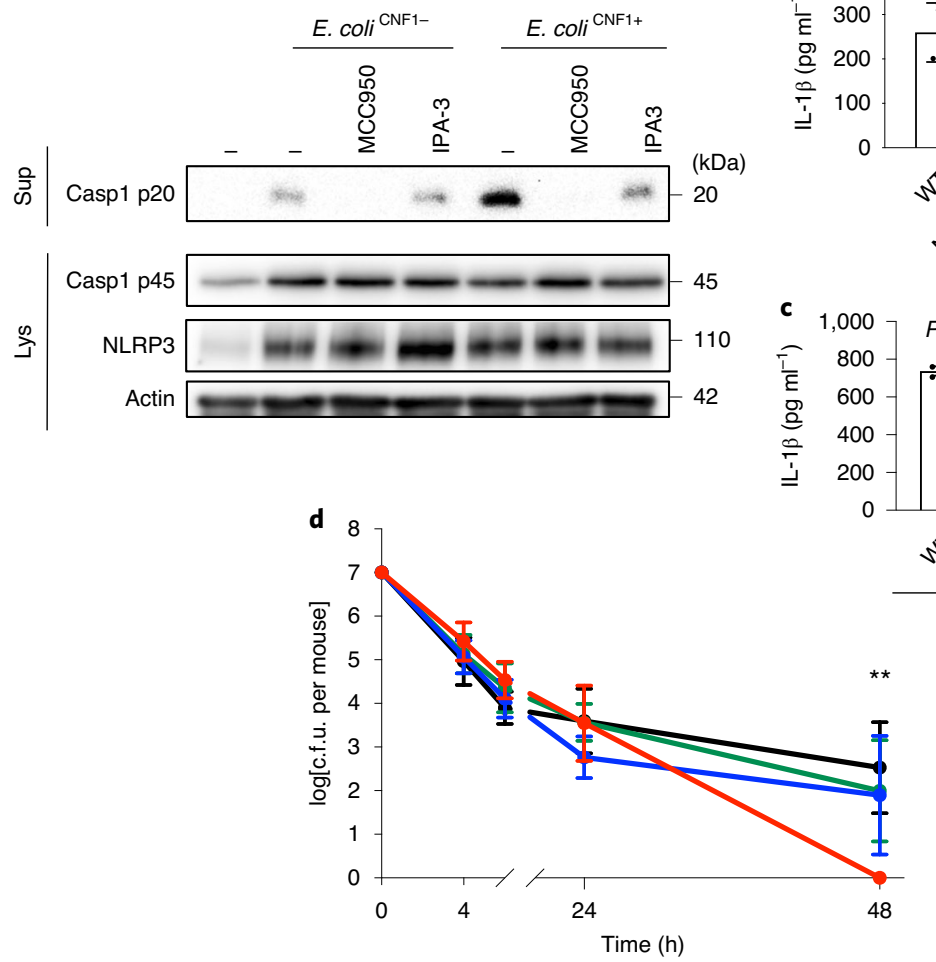
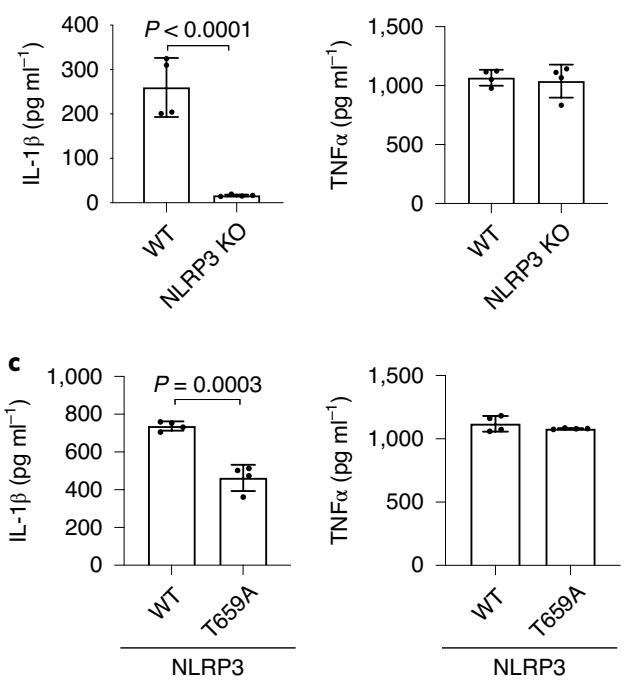

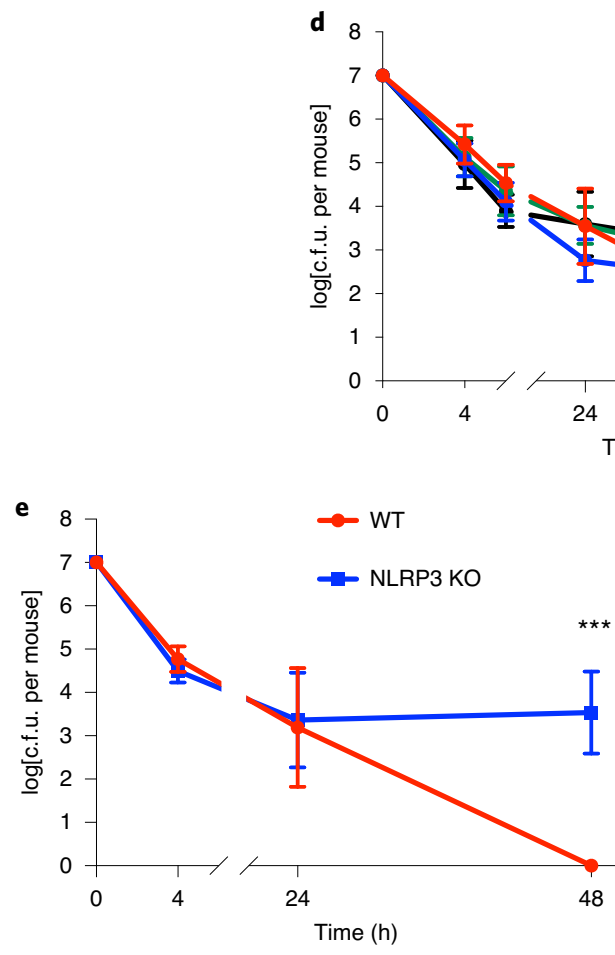

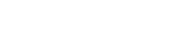
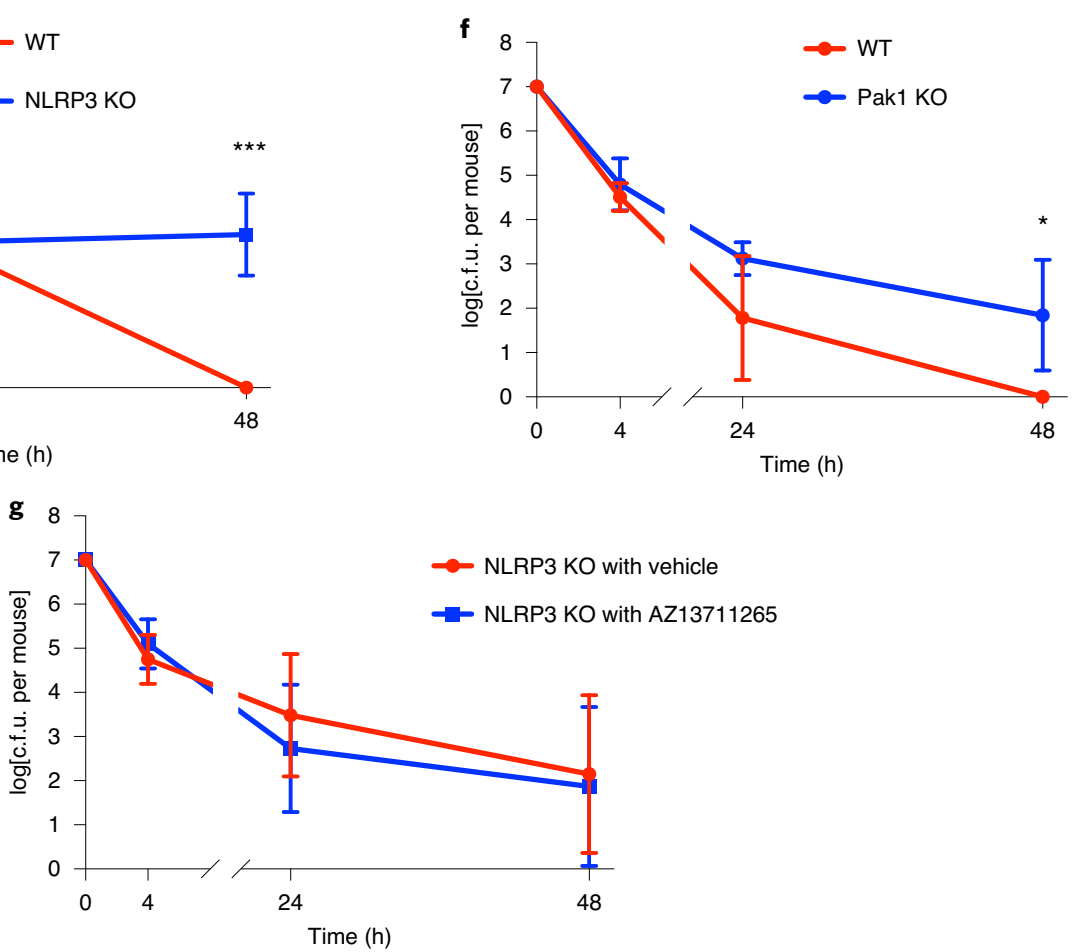
here we show that Rac GTPases that activate bacterial factors are sensed by NLRP3 independently of the type of modification made. Similarly, bacterial factors that inactivate RhoA activate Pyrin independently of the type of modifications ${ }^{12,42,43}$. These results suggest that the host guarding of Rho GTPase signalling integrity relies on two sensors that monitor the abnormal Rho GTPase cycling rather than toxin-triggered post-translational modifications of host proteins or virulence factor enzymatic activities. Interestingly, both Pyrin and NLRP3 require regulation by the serine-threonine kinases PKN1/2 and Pak1/2, respectively. The fact that two different inflammasomes have been evolutionarily selected to detect bacterial toxins that modify Rho GTPases highlights the importance of Rho GTPases in innate immunity.

Further studies are necessary to determine the in vivo conservation of the Pak-NLRP3 axis and whether the sensing of other Rho-GTPase-activating virulence factors by the NLRP3 inflammasome impacts the bacterial burden during infection. Similarly, we expect that further studies will determine the importance of other inflammasomes in detecting bacterial virulence factors that are endowed with enzymatic activities.

Our results reveal the importance of Pak1 and NLRP3 in controlling the bacterial burden during bacteraemia in mice. Even though further studies will be required to determine the role of the Pak-NLRP3 signalling axis in patients with bacteraemia, our results showing an increase in bacterial burden in MCC950-treated mice suggest that caution will be necessary for the use of NLRP3 inhibitors in the clinical setting. This is consistent with clinical data showing that there is an increased risk of infections associated with IL-1 signalling inhibition ${ }^{44,45}$. One option would be to consider combining inflammasome inhibitors with antibiotherapies or with an enhanced surveillance for a potential for bacteraemia risk.

\section{Methods}

Ethics statement. This study was carried out in strict accordance with the guidelines of the Council of the European Union (Directive 86/609/EEC) regarding the protection of animals used for experimental and other scientific purposes. The protocol was approved by the Institutional Animal Care and Use Committee on the Ethics of Animal Experiments of Nice, France (APAFIS\#18322-20181218099427035 v2 and APAFIS\#24906-2020031614223228 v2).

Bacterial strains and toxins. The E. coli UTI89 clinical isolate was originally obtained from a patient with cystitis ${ }^{46}$ and the isogenic UTI89 $\mathrm{CNF}^{+}\left(\right.$E. coli $\left.^{\mathrm{CNF} 1+}\right)$ or UTI89 $\mathrm{CNF}^{-}\left(\right.$E. coli $\left.{ }^{\mathrm{CNF} 1-}\right)$ streptomycin-resistant strain generation and culture conditions were previously described ${ }^{11}$. For the infections, a 1/100 dilution of an overnight culture was inoculated and grown up to an optical density at $600 \mathrm{~nm}$ of 1.2 using a Luria-Bertani (LB) medium supplemented with streptomycin $\left(200 \mu \mathrm{g} \mathrm{ml}^{-1}\right)$. Bacteria were collected by centrifugation and washed twice in PBS before dilution in PBS to obtain the desired bacterial concentrations for the mouse infection experiments. Recombinant WT CNF1 and its catalytically inactive form $\left(\mathrm{CNF}^{\mathrm{C} 866 \mathrm{~S}}\right)$ were produced and purified as previously reported ${ }^{47,48}$. The recombinant DNT toxin was purified from pQEDNTwt using the same protocol $^{49}$. The recombinant proteins were passed through a polymyxin B column (Affinity Detoxi-Gel, Pierce). The removal of endotoxin was verified using a colorimetric limulus amebocyte lysate (LAL) assay (LAL QCL-1000, Cambrex). Each stock of the CNF1 preparation $\left(2 \mathrm{mg} \mathrm{ml}^{-1}\right)$ was shown to contain less than 0.5 endotoxin units per ml. Plasmid expressing the virulence factor pCMV-SopE-HA was previously reported ${ }^{22}$ and SopE expression was stabilized by adding MG132 $(10 \mu \mathrm{M})$ to the cells to block its proteasomal degradation as previously described ${ }^{5}$. Plasmids expressing the pRK5-Myc-DNT were obtained by PCR amplification of pQEDNTwt, and pCMV-HA-YopE was obtained by PCR amplification and subcloning from pACY184-YopE-GSK (gift from I. Brodsky). All of the plasmids were verified by sequencing (Eurofins).

Cell culture, transfection and inhibitors. HEK293T cells were obtained from ATCC (CRL-3216) and maintained according to the ATCC instructions. BMDMs were extracted from the femurs of BALB/c, C57BL/6J, C57BL/6J knockin or $\mathrm{C} 57 \mathrm{BL} / 6 \mathrm{~J}$ knockout mice (aged 6-10 weeks) as indicated in the legends and were cultured in RPMI GlutaMax medium (Life Technologies) supplemented with $100 \mathrm{ng} \mathrm{ml}^{-1} \mathrm{M}$-CSF (premium grade, Miltenyi Biotec), $10 \%$ heat-inactivated FBS (Biowest) and $50 \mu \mathrm{g} \mathrm{ml}^{-1}$ gentamycin (Life Technologies) at $37^{\circ} \mathrm{C}$ in an atmosphere containing $5 \% \mathrm{CO}_{2}$. The cells were seeded at a concentration of $10^{6}$ cells per well in a six-well plate. After $6 \mathrm{~d}$ of differentiation, BMDMs were used for experiments. HEK293T cells were transfected with plasmids using Lipofectamine 2000 (Life Technologies) according to the manufacturer's instructions. siRNAs were transfected in BMDMs for $72 \mathrm{~h}$ using Lipofectamine RNAiMAX Reagent (Thermo Fisher Scientific) according to the manufacturer's instructions. Cells were transfected as indicated in the figure legends with siRNAs (Dharmacon) targeting Nlrp3 (L-053455-00), Rac1 (L-041170-00), Rac2 (L-041171-01), Nek7 (J-063266-09), Pak1 (L-048101-00), Pak2 (L-040615-00) or non-targeting control siRNA (D-001810-10). For the siRNA screen, the BMDMs were transfected with siRNA (Dharmacon) targeting Nod1 (L-055182-00), Nod2 (L-052735-00), Nlrc3 (L-052823-01), Nlrc4 (L-055000-00), Nlrc5 (L-067620-01), Nlrx1 (L-057712-01), Ciita (L-043166-02), Naip1 (L-047682-00), Naip2 (L-044151-01), Naip5 (L-044142 01), Naip6 (L-044145-01), Naip7 (L-065757-00), Nlrp1a (L-066229-00), Nlrp1b (L-161107-01), Nlrp2 (L-053528-01), Nlrp3 (L-053455-01), Nlrp4a (L-052395-01), Nlrp4b (L-058181-01), Nlrp4c (L-049416-01), Nlrp4d (L-067051-01), Nlrp4e (L068064-01), Nlrp4f(L-052668-01), Nlrp4g (L-066364-01), Nlrp5 (L-045315-01), Nlrp6 (L-066157-01), Nlrp9a (L-058269-01), Nlrp9b (L-066417-01), Nlrp9c (L057344-01), Nlrp10 (L-056559-01), Nlrp12 (L-060234-01), Nlrp14 (L-066093-01), Pycard (L-051439-01), Mefv (L-048693-01) and Aim2 (L-044968-01). BMDMs were pretreated with the following inhibitors for $45 \mathrm{~min}: 1 \mu \mathrm{M} \mathrm{CP}-456773$ or MCC950 (Sigma-Aldrich), $5 \mu$ M IPA-3 (Tocris), $1 \mu$ M FRAX597 (Tocris) or the indicated concentration of AZ13711265 (AGV Discovery) in 2\% FBS containing RPMI followed by the addition of CNF1 $500 \mathrm{ng} \mathrm{ml}^{-1}$ and/or ultrapure LPS $100 \mathrm{ng} \mathrm{ml}^{-1}$ (Invivogen) as indicated in the figure legends. Cells treated with nigericin $5 \mu \mathrm{M}$ (Invivogen) or ATP $5 \mathrm{mM}$ (Invivogen) for $30 \mathrm{~min}$ were used as positive control for NLRP3 inflammasome activation. For $\mathrm{K}^{+}$-efflux-preventing experiments, BMDMs were treated with $10 \mathrm{mM}, 20 \mathrm{mM}$ or $40 \mathrm{mM} \mathrm{KCl}$. Primary macrophages were infected with $E$. coli ${ }^{\mathrm{CNF} 1+}$ or the isogenic $E$. coli ${ }^{\mathrm{CNF} 1-}(\mathrm{m} . \mathrm{o} . \mathrm{i} .=5)$ for $16 \mathrm{~h}$. Immortalized NLRP3-knockout BMDMs were stably complemented with pINDUCER21 plasmids encoding human NLPR3 WT or NLRP3 ${ }^{\text {T659A }}$ under a doxycycline-inducible promoter as previously described ${ }^{51}$. NLRP3 expression was induced by adding $2 \mu \mathrm{g} \mathrm{ml}^{-1}$ doxycycline for $16 \mathrm{~h}$ (Takara Bio). All of the cell lines were authenticated using PCR assays with species-specific primers. Mycoplasma testing was negative.

Mouse model of infection. Female C57BL/6J mice (aged 7 weeks; Charles River Laboratory) were injected intraperitoneally with MCC950 (Sigma-Aldrich) at $50 \mathrm{mg} \mathrm{kg}^{-1}$ every $24 \mathrm{~h}$ or AZ13711265 (AGV Discovery) at $10 \mathrm{mg} \mathrm{kg}^{-1}$ every $24 \mathrm{~h}$ or both. NLRP3-knockout mice were provided by V. Petrilli and were described previously $^{52}$. The Pak1-knockout, GSDMD-knockout and ASC-citrine-knockin mice used in this study were reported previously ${ }^{17,32,53}$. Female NLRP3-knockout or Pak1-knockout and female congenic WT C57BL/6J littermate mice were injected intravenously with $10^{7}$ colony-forming units of E. coli and the determination of bacteraemia was monitored as previously described ${ }^{11}$. Mice were housed with their littermates and kept under a regular $12 \mathrm{~h}-12 \mathrm{~h}$ light-dark cycle at room temperature $\left(20-25^{\circ} \mathrm{C}\right)$ and a relative humidity of $50-70 \%$. Food and water were available ad libitum. Experiments were performed under pathogen-free conditions with randomly chosen animals (same sex, matched by age and body weight). Investigators were blinded for in vivo experiments. Sample size was determined on the basis of our previous research ${ }^{11}$ and using $\mathrm{G}^{\star}$ Power software.

Reconstituted NLRP3 inflammasome in HEK293T cells. HEK293T cells were transfected with plasmids encoding the NLRP3 inflammasome components as previously described ${ }^{21,28}$. HEK293T cells were transfected with plasmids encoding Myc-NLRP3 or NLRP3 mutants, ASC-GFP, mpro-caspase1 and pro-IL-1 $\beta$-Flag. Where indicated in the legend, cells were cotransfected with HA-Rac2, the constitutively active mutant of Rac2 mimicking CNF1-induced deamidation $\mathrm{Rac}^{\mathrm{Q} 61 \mathrm{E}}, \mathrm{Rac}^{\mathrm{Q} 61 \mathrm{~L}}, \mathrm{Rac}^{\mathrm{G} 12 \mathrm{~V}}$ or Rac2 ${ }^{\mathrm{T} 17 \mathrm{~N}}$, a dominant negative mutant of Rac2 for $16 \mathrm{~h}$. The monitoring of caspase- 1 or IL-1 $\beta$ cleavage was performed using supernatant immunoblotting.

Immunoprecipitation. HEK293T cells were transfected with plasmids encoding Myc-NLRP3, Myc-NLRP3 ${ }^{\text {S163A S198A T659A }}$, Myc-NLRP3 ${ }^{\text {S163A }}$ and Myc-NLRP3 ${ }^{\text {T659A }}$ GFP-NLRP3, Myc-Pak1 ${ }^{\mathrm{T} 423 \mathrm{E}}$ and HA-Rac2 ${ }^{\mathrm{Q} 61 \mathrm{E}}$, or NLRP3 expression was induced by adding $2 \mu \mathrm{g} \mathrm{ml}^{-1}$ doxycycline for $16 \mathrm{~h}$ to iBMDMs stably expressing NLPR3 or NLRP3 ${ }^{\mathrm{T} 659 \mathrm{~A}}$. Cells were lysed and processed for immunoprecipitation using $2 \mu \mathrm{g}$ of anti-Myc or $3 \mu \mathrm{g}$ of anti-Nek7 antibodies according to previously described conditions ${ }^{54}$. The expression of NLRP3 and endogenous levels of Nek7 were monitored in the cell lysate as well as in the immunoprecipitated fraction.

LDH release. The supernatant of stimulated macrophages was collected and centrifuged at $300 \mathrm{~g}$ for $5 \mathrm{~min}$ to remove cellular debris. LDH measurement was performed using the LDH Cytotoxicity Assay Kit (Thermo Fisher Scientific) according to the manufacturer's instructions, in samples diluted 1:5 in PBS. Data were plotted as the percentage of LDH release considering a Triton X-100 treated well as $100 \%$.

Cell permeabilization kinetics. BMDMs were plated and stimulated in a 96-well plate in medium containing propidium iodide $\left(0.1 \mu \mathrm{g} \mathrm{ml}^{-1}\right)$ and data were acquired with $\mathrm{a} \times 10$ objective using the IncuCyte Zoom system v.6.2.9200.0 
(Essen BioScience) under a $\mathrm{CO}_{2}$ - and temperature-controlled environment. Each condition was run in quadruplicate. The number of fluorescent objects was counted using Incucyte Zoom (Essen BioScience).

In vitro kinase assay. Recombinant purified Pak1 (500 ng) was incubated with $1 \mu \mathrm{g}$ of recombinant human NLRP3 protein (Abcam, ab165022), and with $50 \mu \mathrm{M}$ ATP and $4 \mu \mathrm{Ci}$ of $[\gamma 32 \mathrm{P}] \mathrm{ATP}$ in kinase buffer (50 mM HEPES pH 7.3, $50 \mathrm{mM} \mathrm{NaCl}, 0.05 \%$ Triton X-100, $10 \mathrm{mM} \beta$-glycerophosphate, $5 \mathrm{mM} \mathrm{NaF}, 10 \mathrm{mM} \mathrm{MgCl}_{2}$ and $0.2 \mathrm{mM}$ $\mathrm{MnCl}_{2}$ ) at $30^{\circ} \mathrm{C}$ for $30 \mathrm{~min}$ in a final volume of $39 \mu \mathrm{l}$. The reaction was stopped by adding $15 \mu \mathrm{l}$ of LDS (Thermo Fisher Scientific) and $6 \mu \mathrm{l}$ of dithiothreitol $500 \mathrm{mM}$. Samples were analysed by electrophoresis using Bolt 4-12\% Bis-Tris Plus gels (Thermo Fisher Scientific) followed by Coomassie blue staining and autoradiography.

Immunofluorescence staining, antibodies and ELISA assays. Caspase- 1 activation was detected using the fluorescent probe FAM-FLICA (ImmunoChemistry Technologies) after $6 \mathrm{~h}$ of treatment, according to the manufacturer's instructions. After labelling, cells were fixed in $4 \%$ paraformaldehyde for $15 \mathrm{~min}$, PFA was neutralized with $50 \mathrm{mM} \mathrm{NH}_{4} \mathrm{Cl}$ for $15 \mathrm{~min}$, cells were permeabilized with $0.5 \%$ Triton X-100 for $5 \mathrm{~min}$ and blocked with 2\% TBS-BSA. Cells were incubated with mouse anti-NLRP3 (clone Cryo-2, Adipogen) and/or rabbit anti-ASC (AG-25B-0006, Adipogen) or rabbit anti-phosphorylated-Pak (ab40795, Abcam) antibodies for $1 \mathrm{~h}$ followed by incubation with the secondary antibodies TexasRed anti-mouse IgG (TI-2000, Vector Laboratories) or Cy5 anti-mouse IgG (715-175-151, Jackson Immunoresearch) and/or TexasRed anti-rabbit IgG (711-075-152, Jackson Immunoresearch) and/or phalloidin Alexa Fluor 647 (ab176759, Abcam) and Hoechst 33342 (H1399, Thermo Fisher Scientific) for $30 \mathrm{~min}$. Cells were imaged using a Nikon A1R confocal microscope. The following antibodies were used in this study: rabbit anti-IL-1 $\beta$ (GTX74034, Genetex), mouse anti-caspase-1 (clone Casper-1, Adipogen), mouse anti-Rac (clone 102/Rac1, BD Biosciences), goat anti-Rac2 (ab2244, Abcam), mouse anti-NLRP3 (clone Cryo-2, Adipogen), rabbit anti-Nek7 (ab133514, Abcam), rabbit anti-Pak1 (2602, CST), rabbit anti-Pak2 (2608, CST), rabbit monoclonal anti-GSDMD (ab209845), mouse anti- $\beta$-actin (AC-74, Sigma-Aldrich), mouse anti-Myc (9E10, Roche), mouse anti-HA (16B12, Covance), mouse anti-Flag (clone M2, Sigma-Aldrich), mouse anti-GFP (clone 7.1, 13.1, Roche). Cytokine secretion was determined by ELISA using the mouse Quantikine ELISA kits for mouse IL-6, IL-18, TNF- $\alpha$ and IL-1 $\beta$ (R\&D Systems) according to the manufacturer's instructions.

Flow cytometry analysis. BMDMs isolated from C57BL/6J mice constitutively expressing ASC-citrine fusion protein (R26-CAG-ASC-citrine) were treated with LPS (100 $\mathrm{ng} \mathrm{m}^{-1}$ ) for $16 \mathrm{~h}$ before $6 \mathrm{~h}$ of treatment with vehicle or CNF1 $\left(500 \mathrm{ng} \mathrm{ml}^{-1}\right)$ or $30 \mathrm{~min}$ with nigericin $(5 \mu \mathrm{M})$. Cells were collected and analysed by flow cytometry using a BD FACSCanto II cytometer (BD Biosciences). Cytometry data were analysed using FlowJo v.10.6.2. Doublets were excluded using a side scatter (SSC)-A (area) and SSC-H (height) plot; cells with a high expression of ASC-citrine were gated and then analysed for ASC-citrine signal area (ASCcitrine-A) and ASC-citrine signal height (ASC-citrine-H). Cells with ASC specks were defined with a higher ASC-H:ASC-A ratio.

Statistical analyses. Statistical analyses were performed using GraphPad Prism v.8.2.1. Comparisons of the bacterial load of mice were performed using nonparametric Mann-Whitney $U$-tests. Statistical analyses of FAM-FLICA ${ }^{+}$cells, cytokine secretion and LDH release were performed using unpaired two-tailed Student's $t$-tests.

Reporting Summary. Further information on research design is available in the Nature Research Reporting Summary linked to this article.

\section{Data availability}

All data supporting the findings of this study are available within the Article and its Supplementary Information or from the corresponding author on reasonable request. Source data are provided with this paper.

Received: 21 August 2019; Accepted: 13 November 2020; Published online: 11 January 2021

\section{References}

1. Martin, G. S., Mannino, D. M., Eaton, S. \& Moss, M. The epidemiology of sepsis in the United States from 1979 through 2000. N. Engl. J. Med. 348, 1546-1554 (2003).

2. Vance, R. E., Isberg, R. R. \& Portnoy, D. A. Patterns of pathogenesis: discrimination of pathogenic and nonpathogenic microbes by the innate immune system. Cell Host Microbe 6, 10-21 (2009).

3. Stuart, L. M., Paquette, N. \& Boyer, L. Effector-triggered versus pattern-triggered immunity: how animals sense pathogens. Nat. Rev. Immunol. 13, 199-206 (2013).

4. Flatau, G. et al. Toxin-induced activation of the $\mathrm{G}$ protein $\mathrm{p} 21$ Rho by deamidation of glutamine. Nature 387, 729-733 (1997).
5. Schmidt, G. et al. Gln 63 of Rho is deamidated by Escherichia coli cytotoxic necrotizing factor-1. Nature 387, 725-729 (1997).

6. Aktories, K. \& Barbieri, J. Bacterial cytotoxins: targeting eukaryotic switches. Nat. Rev. Microbiol. 3, 397-410 (2005).

7. Galán, J. E. Common themes in the design and function of bacterial effectors. Cell Host Microbe 5, 571-579 (2009).

8. Bruno, V. M. et al. Salmonella Typhimurium type III secretion effectors stimulate innate immune responses in cultured epithelial cells. PLoS Pathog. 5, e1000538 (2009).

9. Munro, P. et al. Activation and proteasomal degradation of Rho GTPases by cytotoxic necrotizing factor-1 elicit a controlled inflammatory response. J. Biol. Chem. 279, 35849-35857 (2004).

10. Boquet, P. \& Lemichez, E. Bacterial virulence factors targeting Rho GTPases: parasitism or symbiosis? Trends Cell Biol. 13, 238-246 (2003).

11. Diabate, M. et al. Escherichia coli $\alpha$-hemolysin counteracts the anti-virulence innate immune response triggered by the Rho GTPase activating toxin CNF1 during bacteremia. PLoS Pathog. 11, e1004732 (2015).

12. $\mathrm{Xu}, \mathrm{H}$. et al. Innate immune sensing of bacterial modifications of Rho GTPases by the pyrin inflammasome. Nature 513, 237-241 (2014).

13. Groslambert, M. \& Py, B. F. Spotlight on the NLRP3 inflammasome pathway. J. Inflamm. Res. 11, 359-374 (2018).

14. Yang, Y., Wang, H., Kouadir, M., Song, H. \& Shi, F. Recent advances in the mechanisms of NLRP3 inflammasome activation and its inhibitors. Cell Death Dis. 10, 128 (2019)

15. Gao, W., Yang, J., Liu, W., Wang, Y. \& Shao, F. Site-specific phosphorylation and microtubule dynamics control pyrin inflammasome activation. Proc. Natl Acad. Sci. USA 113, E4857-E4866 (2016).

16. Park, Y. H., Wood, G., Kastner, D. L. \& Chae, J. J. Pyrin inflammasome activation and RhoA signaling in the autoinflammatory diseases FMF and HIDS. Nat. Immunol. 17, 914-921 (2016).

17. Tzeng, T. C. et al. A fluorescent reporter mouse for inflammasome assembly demonstrates an important role for cell-bound and free ASC specks during in vivo Infection. Cell Rep. 16, 571-582 (2016).

18. Sester, D. P. et al. Assessment of inflammasome formation by flow cytometry. Curr. Protoc. Immunol. 114, 14.40.1-14.40.29 (2016)

19. Lamkanfi, M. \& Dixit, V. M. In retrospect: the inflammasome turns 15. Nature 548, 534-535 (2017).

20. He, Y., Hara, H. \& Núñez, G. Mechanism and regulation of NLRP3 inflammasome activation. Trends Biochem. Sci. 41, 1012-1021 (2016).

21. Shi, H., Murray, A. \& Beutler, B. Reconstruction of the mouse inflammasome system in HEK293T cells. Bio. Protoc. 6, e1986 (2016).

22. Keestra, A. M. et al. Manipulation of small Rho GTPases is a pathogeninduced process detected by NOD1. Nature 496, 233-237 (2013).

23. Doye, A. et al. CNF1 exploits the ubiquitin-proteasome machinery to restrict Rho GTPase activation for bacterial host cell invasion. Cell 111, 553-564 (2002).

24. Boyer, L. et al. Pathogen-derived effectors trigger protective immunity via activation of the Rac2 enzyme and the IMD or Rip kinase signaling pathway. Immunity 35, 536-549 (2011).

25. Manser, E., Leung, T., Salihuddin, H., Zhao, Z. S. \& Lim, L. A brain serine/ threonine protein kinase activated by Cdc42 and Rac1. Nature 367, 40-46 (1994).

26. Wells, C. M. \& Jones, G. E. The emerging importance of group II PAKs. Biochem. J. 425, 465-473 (2010).

27. Semenova, G. \& Chernoff, J. Targeting PAK1. Biochem. Soc. Trans. 45, 79-88 (2017).

28. Song, N. et al. NLRP3 phosphorylation is an essential priming event for inflammasome activation. Mol. Cell 68, 185-197 (2017).

29. Sharif, H. et al. Structural mechanism for NEK7-licensed activation of NLRP3 inflammasome. Nature 570, 338-343 (2019).

30. Coll, R. C. et al. A small-molecule inhibitor of the NLRP3 inflammasome for the treatment of inflammatory diseases. Nat. Med. 21, 248-255 (2015).

31. Kelly, M. L. \& Chernoff, J. Mouse models of PAK function. Cell Logist. 2, 84-88 (2012).

32. Shi, J. et al. Cleavage of GSDMD by inflammatory caspases determines pyroptotic cell death. Nature 526, 660-665 (2015).

33. He, W. T. et al. Gasdermin D is an executor of pyroptosis and required for interleukin-1 $\beta$ secretion. Cell Res. 25, 1285-1298 (2015).

34. Broz, P., Pelegrín, P. \& Shao, F. The gasdermins, a protein family executing cell death and inflammation. Nat. Rev. Immunol. 20, 143-157 (2020).

35. Rühl, S. et al. ESCRT-dependent membrane repair negatively regulates pyroptosis downstream of GSDMD activation. Science 362, 956-960 (2018).

36. Evavold, C. L. et al. The pore-forming protein gasdermin D regulates interleukin-1 secretion from living macrophages. Immunity $\mathbf{4 8}$, 35-44 (2018).

37. Monteleone, $M$. et al. Interleukin-1 $\beta$ maturation triggers its relocation to the plasma membrane for gasdermin-D-dependent and -independent secretion. Cell Rep. 24, 1425-1433 (2018). 
38. Pandori, W. J. et al. Toxoplasma gondii activates a Syk-CARD9-NF-кB signaling axis and gasdermin D-independent release of IL- $1 \beta$ during infection of primary human monocytes. PLoS Pathog. 15, e1007923 (2019).

39. Muessel, M. J., Harry, G. J., Armstrong, D. L. \& Storey, N. M. SDF-1 $\alpha$ and LPA modulate microglia potassium channels through rho GTPases to regulate cell morphology. Glia 61, 1620-1628 (2013).

40. Jones, J. D. \& Dangl, J. L. The plant immune system. Nature 444, 323-329 (2006).

41. Lopes Fischer, N., Naseer, N., Shin, S. \& Brodsky, I. E. Effector-triggered immunity and pathogen sensing in metazoans. Nat. Microbiol. 5, 14-26 (2020).

42. Aubert, D. F. et al. A Burkholderia type VI effector deamidates Rho GTPases to activate the pyrin inflammasome and trigger inflammation. Cell Host Microbe 19, 664-674 (2016).

43. Medici, N. P., Rashid, M. \& Bliska, J. B. Characterization of pyrin dephosphorylation and inflammasome activation in macrophages as triggered by the yersinia effectors YopE and YopT. Infect. Immun. 87, e00822-18 (2019).

44. Cabral, V. P., Andrade, C. A., Passos, S. R., Martins, M. F. \& Hökerberg, Y. H. Severe infection in patients with rheumatoid arthritis taking anakinra rituximab, or abatacept: a systematic review of observational studies. Rev. Bras. Reumatol. Engl. Ed. 56, 543-550 (2016).

45. Ridker, P. M. et al. Antiinflammatory therapy with canakinumab for atherosclerotic disease. N. Engl. J. Med. 377, 1119-1131 (2017).

46. Mulvey, M. A., Schilling, J. D. \& Hultgren, S. J. Establishment of a persistent Escherichia coli reservoir during the acute phase of a bladder infection. Infect. Immun. 69, 4572-4579 (2001).

47. Buetow, L., Flatau, G., Chiu, K., Boquet, P. \& Ghosh, P. Structure of the Rho-activating domain of Escherichia coli cytotoxic necrotizing factor 1 . Nat. Struct. Biol. 8, 584-588 (2001).

48. Doye, A., Boyer, L., Mettouchi, A. \& Lemichez, E. Ubiquitin-mediated proteasomal degradation of Rho proteins by the CNF1 toxin. Methods Enzymol. 406, 447-456 (2006).

49. Matsuzawa, T., Kashimoto, T., Katahira, J. \& Horiguchi, Y. Identification of a receptor-binding domain of Bordetella dermonecrotic toxin. Infect. Immun. 70, 3427-3432 (2002).

50. Kubori, T. \& Galán, J. E. Temporal regulation of salmonella virulence effector function by proteasome-dependent protein degradation. Cell 115, 333-342 (2003).

51. Lagrange, B. et al. Human caspase-4 detects tetra-acylated LPS and cytosolic Francisella and functions differently from murine caspase-11. Nat. Commun. 9, 242 (2018).

52. Martinon, F., Pétrilli, V., Mayor, A., Tardivel, A. \& Tschopp, J. Goutassociated uric acid crystals activate the NALP3 inflammasome. Nature 440 237-241 (2006).

53. McDaniel, A. S. et al. Pak1 regulates multiple c-Kit mediated RasMAPK gain-in-function phenotypes in $\mathrm{Nf1}^{+/-}$mast cells. Blood 112 4646-4654 (2008).

54. Stutz, A. et al. NLRP3 inflammasome assembly is regulated by phosphorylation of the pyrin domain. J. Exp. Med. 214, 1725-1736 (2017).

\section{Acknowledgements}

We thank P. Auberger, A. Baumler, I. Brodsky, J. Chernoff, D. Golenbock, T. Henry, M. Keestra-Gounder, E. Lemichez, E. Manser, E. Meunier, V. Petrilli, D. Pisani, J.-E. Ricci, G. Robert, P.-M. Roger, L. Stuart, P. Vandenabeele, S. Ivanov and L. Yvan-Charvet for sharing materials or discussions; A.-S. Dufour, E. Garcia, M. Irondelle and J. Murdaca for technical assistance; members of the Innate Sensors Community (InnaSCo) for sharing tools; A. Cuttriss and staff at the Office of International Scientific Visibility of Université Côte d'Azur for professional language editing; staff at the Etablissement Français du Sang of Marseille for providing human blood from human healthy donors; and staff at the C3M facilities (animal, genomic, cytometry and imaging) and the Harvard Taplin mass spectrometry core. The mouse strain used for this research project, B6.129S2-Pak1tm1Cher/Mmnc (RRID, MMRRC_031838-UNC) was obtained from the Mutant Mouse Resource and Research Center (MMRRC) at University of North Carolina at Chapel Hill, an NIH-funded strain repository, and was donated to the MMRRC by J. Chernoff, Fox Chase Cancer Center. This work was supported by grants from the ANR (ANR-17-CE15-0001), Investments for the Future programs LABEX SIGNALIFE ANR-11-LABX-0028-01, IDEX UCA ${ }^{\text {IEDI }}$ ANR-15-IDEX-01, ARC (RAC15014AAA), Université Côte d'Azur, Infectiopole sud and REDPIT. B.F.P. is supported by ERC (ERC2013-CoG_616986). A.M. is supported by a fellowship from FRM; C.T. by a fellowship from Ville de Nice; and O.D. by a fellowship from INSERM and Université Côte d'Azur.

\section{Author contributions}

O.D. and A.D. designed, performed and analysed most of the experiments with input from C.T., C.L., A.J., A.G., A.M., P.C., A.R. and S.M.; J.C. and R.R. provided advice on the mice infection model. E.V., R.R.G., D.C., B.F.P., A.R., P.H.V.S. and M.L. provided tools and advice on NLRP3 inflammasome regulation. P.M. generated NLRP3 mutants and, with G.M. and O.D., performed and analysed most of the in vivo experiments. O.V. performed virulence factor and toxin subcloning, protein purifications, the in vitro kinase assay and analysed the mass spectrometry results. L.B. conceived the project, designed experiments and wrote the manuscript

\section{Competing interests}

The authors declare no competing interests.

\section{Additional information}

Extended data is available for this paper at https://doi.org/10.1038/s41564-020-00832-5. Supplementary information is available for this paper at https://doi.org/10.1038/ s41564-020-00832-5.

Correspondence and requests for materials should be addressed to L.B.

Peer review information Nature Microbiology thanks Igor Brodsky, Gad Frankel and the other, anonymous, reviewer(s) for their contribution to the peer review of this work.

Reprints and permissions information is available at www.nature.com/reprints. Publisher's note Springer Nature remains neutral with regard to jurisdictional claims in published maps and institutional affiliations.

(C) The Author(s), under exclusive licence to Springer Nature Limited 2021 
a

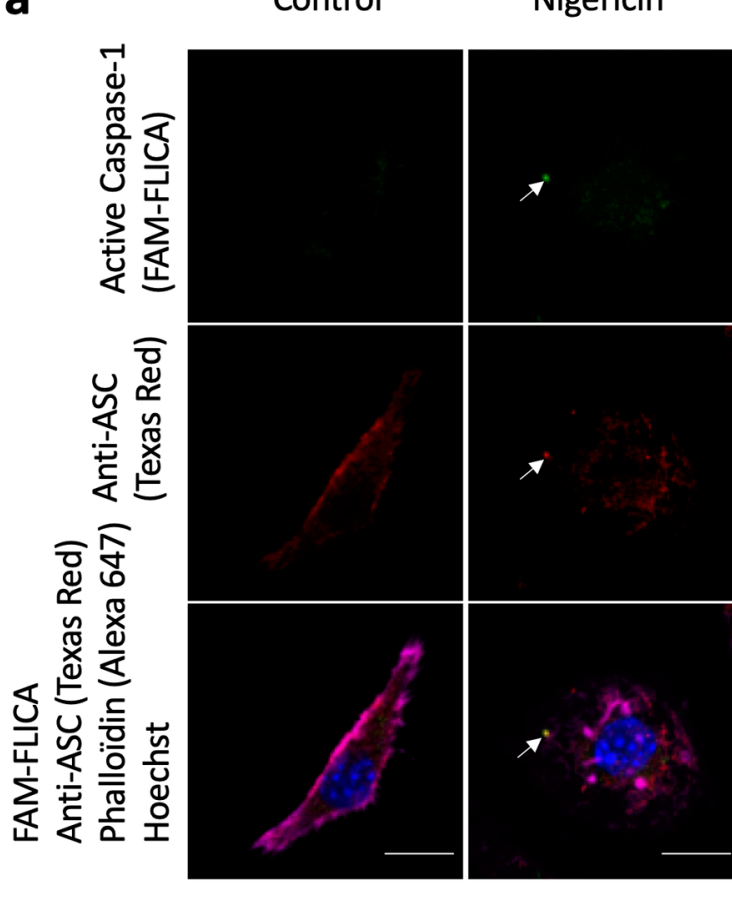

CNF1

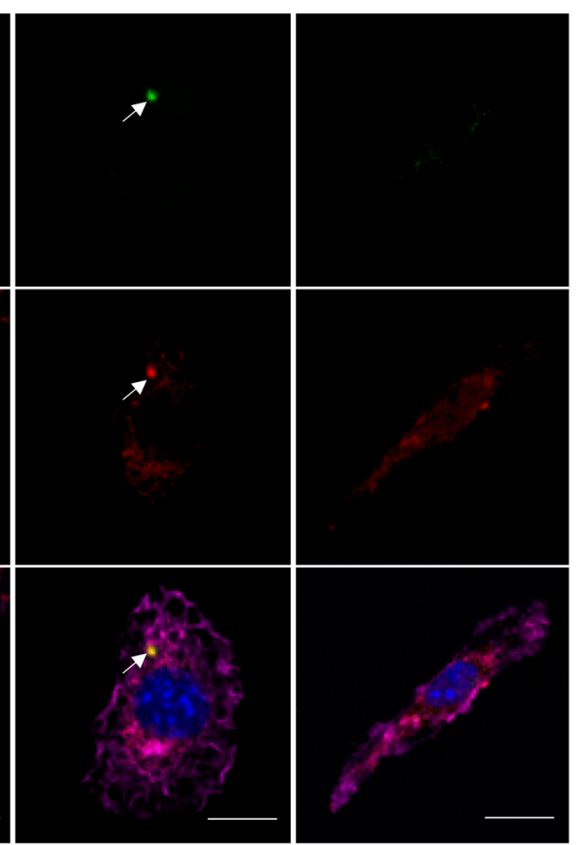

b

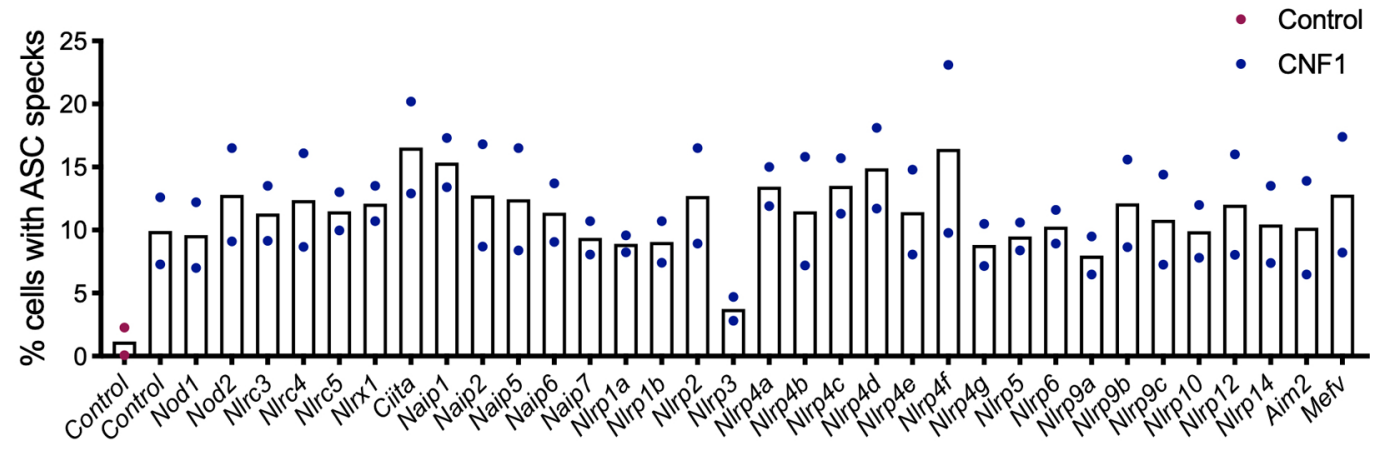

C
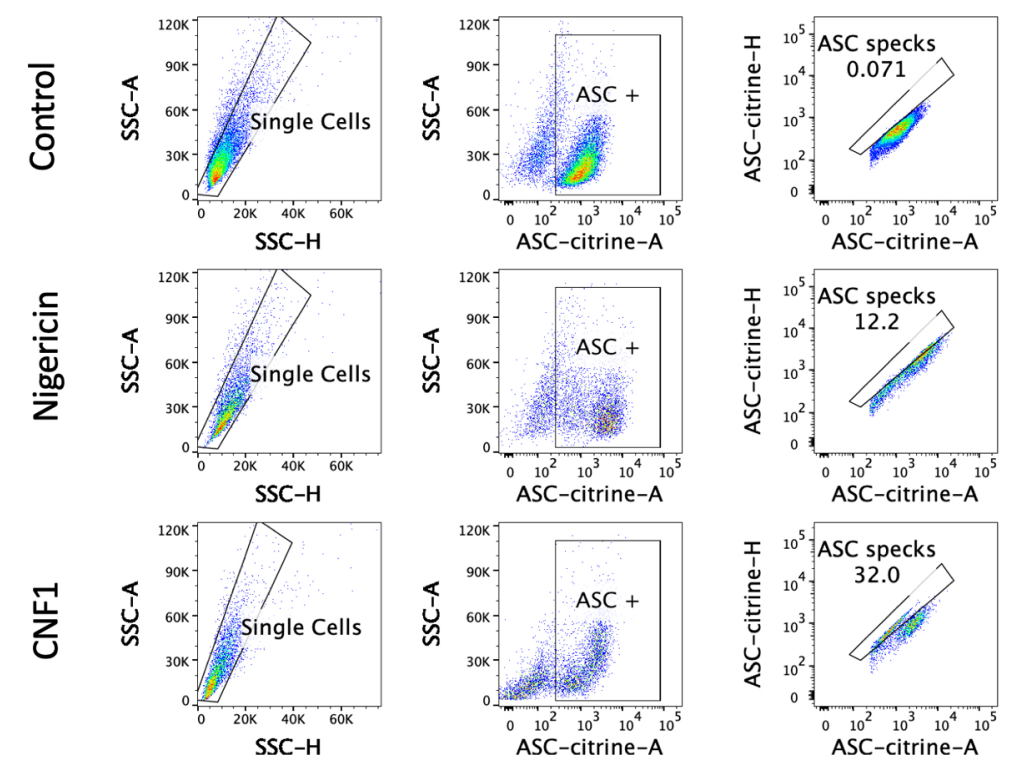

Extended Data Fig. 1 | See next page for caption. 
Extended Data Fig. 1 | CNF1 triggers Caspase-1 activation and ASC specks formation. a, BMDMs isolated from BALB/C mice were either treated with vehicle (control) or CNF1 (500 $\left.\mathrm{ng} \mathrm{ml}^{-1}\right)$, inactive catalytic mutant CNF1 C866S (500 ng/mL) for $6 \mathrm{~h}$, or Nigericin $(5 \mu \mathrm{M})$ for 30 min. Active Caspase-1 was revealed with FAM-FLICA (green), ASC was stained using an anti-ASC antibody (Texas Red), nuclei and actin filament were stained with Hoechst and phalloidin-Alexa 647 respectively. Cells were analyzed by confocal microscopy. Arrows indicates FAM-FLICA dots that colocalize with the ASC staining. Scale bar: $10 \mu \mathrm{m}$. b, BMDM isolated from C57BL/6 J mice constitutively expressing ASC-citrine fusion protein (R26-CAG-ASC-citrine) were transfected with the indicated siRNA for $72 \mathrm{~h}$ prior to $6 \mathrm{~h}$ of CNF1 treatment $(500 \mathrm{ng} / \mathrm{mL})$ or treated with vehicle (control). Percent of cells with ASC specks. Data are expressed as the mean \pm SEM. Each dot represents $10^{5}$ cells $(n=2$ biologically independent samples). $\mathbf{c}, \mathrm{BMDM}$ isolated from C57BL/6 J mice constitutively expressing ASC-citrine fusion protein (R26-CAG-ASC-citrine) were treated $6 \mathrm{~h}$ with CNF1 (500 ng/mL) or Nigericin ( $5 \mu \mathrm{M}$ ) for $30 \mathrm{~min}$ or vehicle (control). Cells were analyzed for ASC speck formation by flow cytometry as indicated, doublets were excluded using SSC-A and SSC-H plot, cells with a high expression of ASC-citrine were gated and then analyzed for ASC-citrine area (ASC-citrine-A) and ASC-citrine height (ASC-citrine-H). Cells with ASC specks are defined with a higher ASC-H:ASC-A ratio. Experiments were repeated at least three times, and representative data are shown. 
a

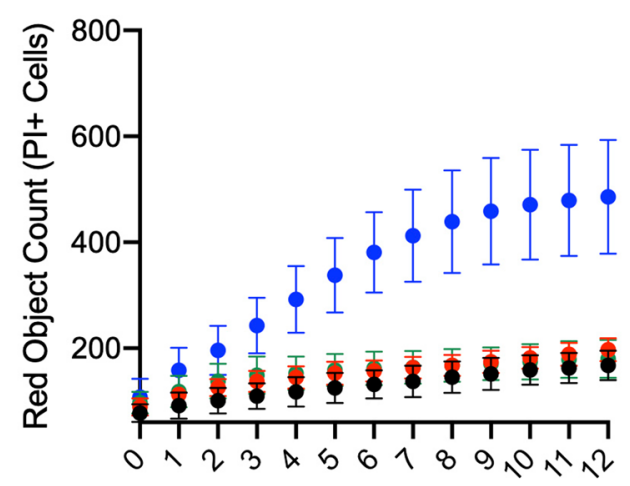

Time to PI positivity (h)

b

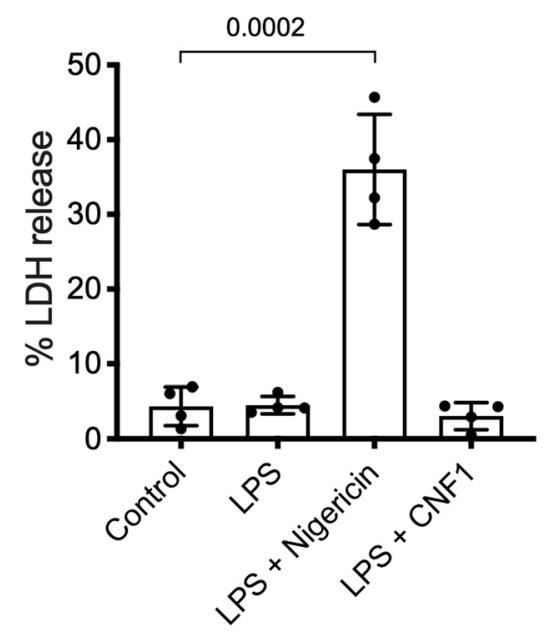

d

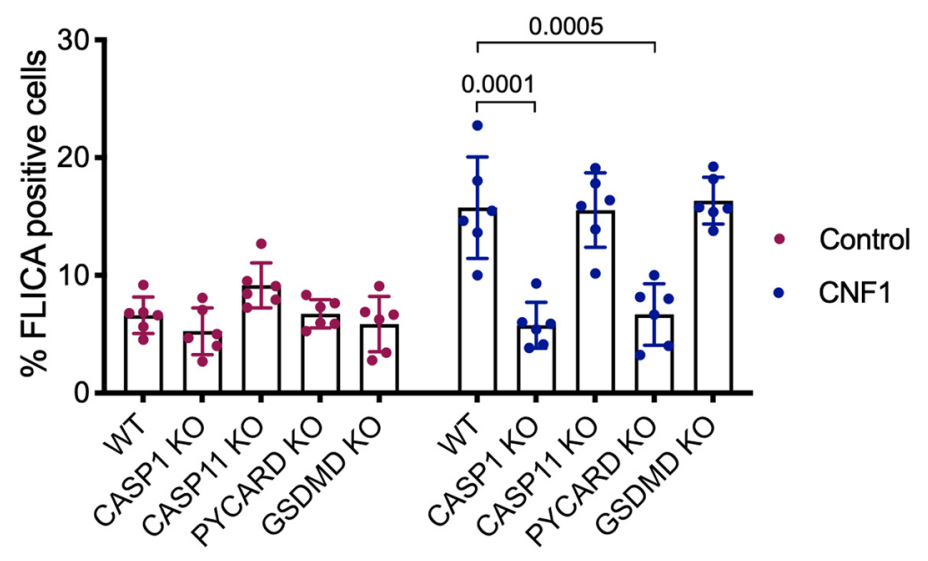

C

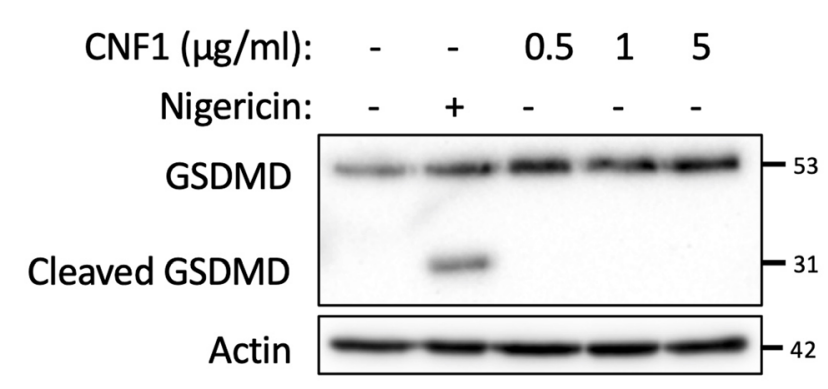

e

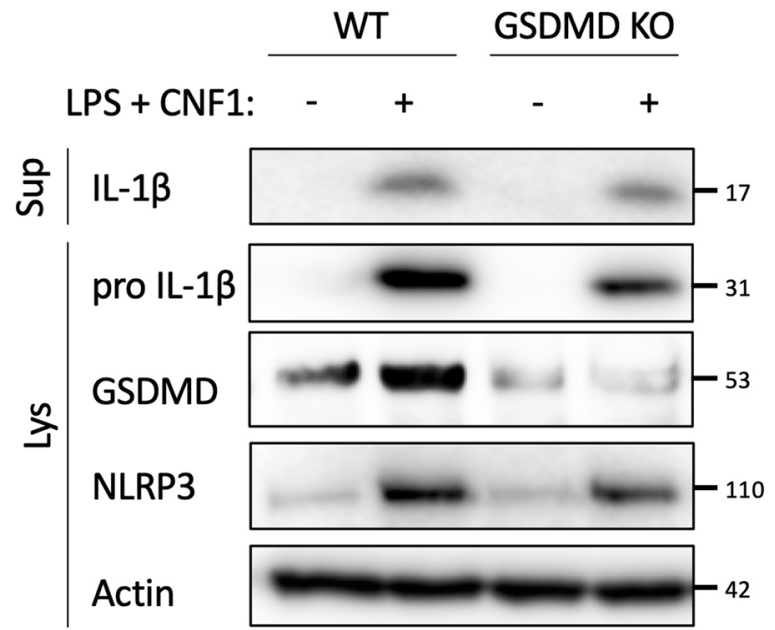

Extended Data Fig. 2 | See next page for caption.

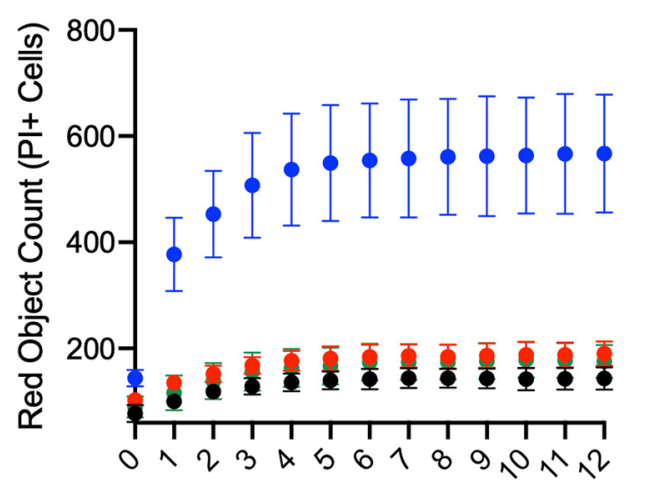

Time to PI positivity (h)

- Control

- CNF1 $0.5 \mu \mathrm{g} / \mathrm{mL}$

- CNF1 $5 \mu \mathrm{g} / \mathrm{mL}$ 
Extended Data Fig. 2 | NLRP3 inflammasome activation by CNF1 does not induce pyroptosis. a, BMDMs isolated from C57BL/6 J mice were treated with vehicle (control), Nigericin $(5 \mu \mathrm{M})$ or CNF1 $(500 \mathrm{ng} / \mathrm{mL}$ or $5 \mu \mathrm{g} / \mathrm{mL})$ with or without LPS $(100 \mathrm{ng} / \mathrm{mL})$. Propidium iodide (PI) uptake was monitored over time (red object count) by real time imaging. Data are expressed as mean \pm SD. $10^{4}$ cells were analyzed for each replicate $(n=4$ independent wells). b, BMDMs isolated from C57BL/ $6 \mathrm{~J}$ mice were treated with vehicle (control, $n=6$ independent experiments), LPS (100 ng $/ \mathrm{mL}, \mathrm{n}=4 \mathrm{independent}$ experiments), LPS and CNF1 (500 ng/mL, $\mathrm{n}=6$ independent experiments) or LPS and Nigericin $(5 \mu \mathrm{M}, \mathrm{n}=4$ independent experiments), and LDH release was assessed. Data are expressed as the mean \pm SEM. Statistical analyses were performed using a two-tailed nonparametric Mann Whitney test. c, BMDMs isolated from C57BL/6 J mice were treated either with Nigericin $(5 \mu \mathrm{M})$ for 30 min or CNF1 $(0.5,1$ or $5 \mu \mathrm{g} / \mathrm{mL})$ for $8 \mathrm{~h}$ and GSDMD cleavage in cell lysates is shown. d, BMDMs isolated from C57BL/6 J wild-type or CASP1, CASP11, PYCARD (coding for ASC) or GSDMD knock-out mice were untreated or treated with CNF1 $(500 \mathrm{ng} / \mathrm{mL})$ for $6 \mathrm{~h}$ and were analyzed for Caspase-1 activation using the FAM-FLICA probe. Data are expressed as the mean \pm SEM. Statistical analyses were performed using a two-tailed unpaired Student's t-test. Each dot represents 100 cells ( $n=700$ cells). e, BMDMs isolated from wild-type or GSDMD knock-out mice were treated with CNF1 $(500 \mathrm{ng} / \mathrm{mL})$ and LPS $(100 \mathrm{ng} / \mathrm{mL})$ for $8 \mathrm{~h}$ as indicated. Supernatants and cell lysates were analyzed by immunoblot. The numbers on the side of the immunoblots indicate molecular weight $(\mathrm{kDa})$. Experiments were repeated at least three times, and representative data are shown. 


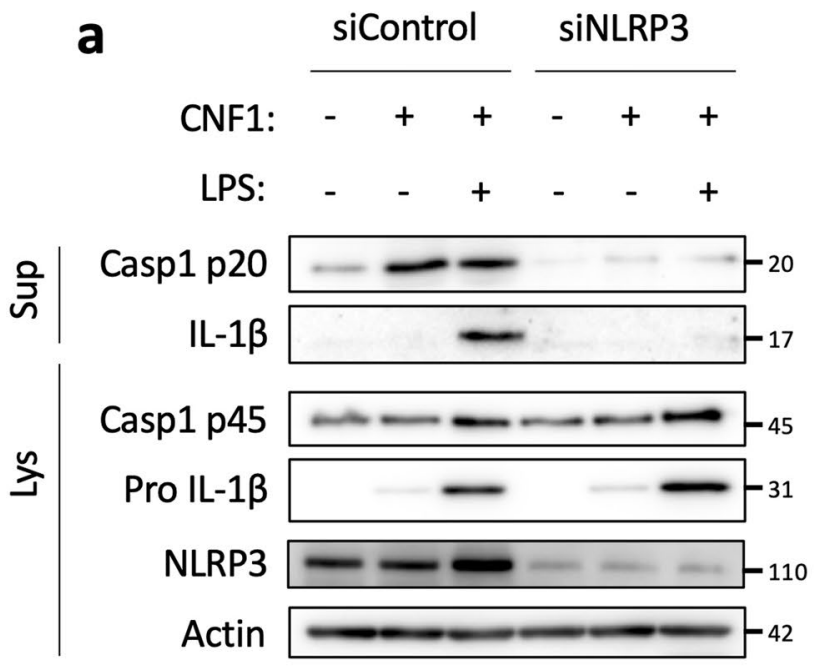

C

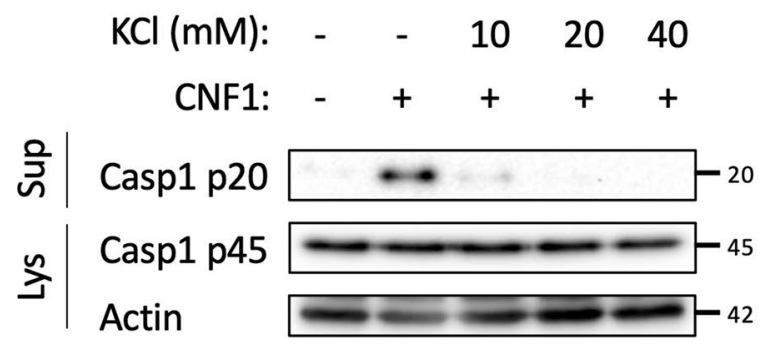

b

CNF1:

\begin{tabular}{cccccc}
\multicolumn{2}{c}{ siControl } & & \multicolumn{2}{c}{ siNek7 } \\
\cline { 1 - 1 }$++_{-}$ & + & - & + & - & + \\
- & + & + & - & - & +
\end{tabular}
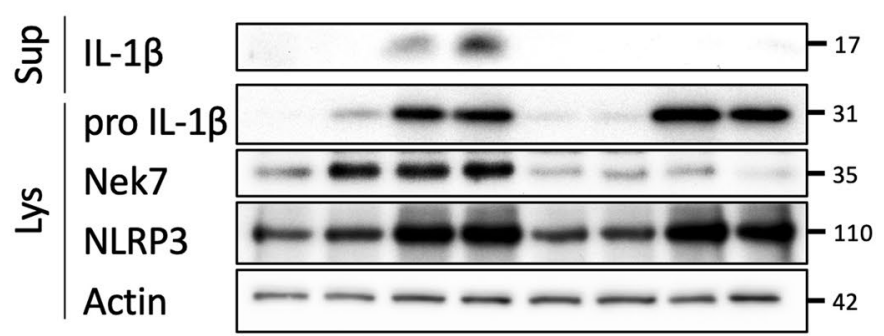

d

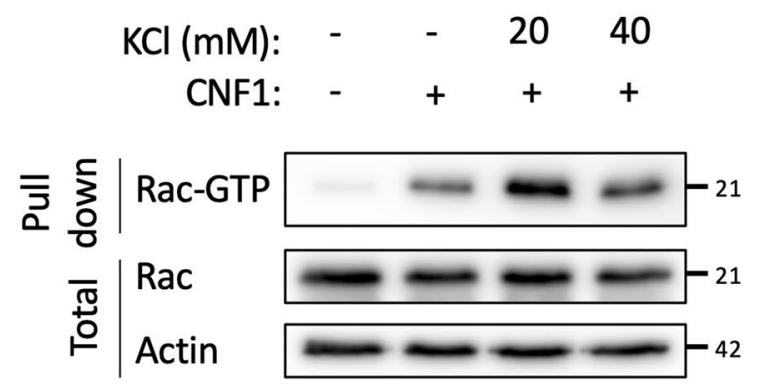

Extended Data Fig. 3 | CNF1-triggered inflammasome activation depends on NLRP3, Nek7 and K+ efflux. a,b, BMDMs isolated from C57BL/6 J mice were transfected with siRNA-targeting NLRP3 (a), siRNA-targeting Nek7 (b), or control non-targeting siRNA for $72 \mathrm{~h}$ before treatment with CNF1 (500 ng/mL) and/or LPS $(100 \mathrm{ng} / \mathrm{mL})$ for $8 \mathrm{~h}$. Supernatants and cell lysates were analyzed by immunoblot. c,d, BMDMs isolated from C57BL/6 J mice (c) or iBMDMs (d) were treated with the indicated $\mathrm{KCl}$ concentration and CNF1 $(500 \mathrm{ng} / \mathrm{mL}$ ) for $8 \mathrm{~h}$. c, Supernatants and cell lysates were analyzed by immunoblot, or (d) cell lysates were analyzed using a GST-Pak-RBD pull-down assay. The Rac associated with the GST-Pak-RBD beads is indicated as Rac-GTP. The numbers on the side of the immunoblots indicate molecular weight $(\mathrm{kDa})$. Experiments were repeated at least three times, and representative data are shown. 
a

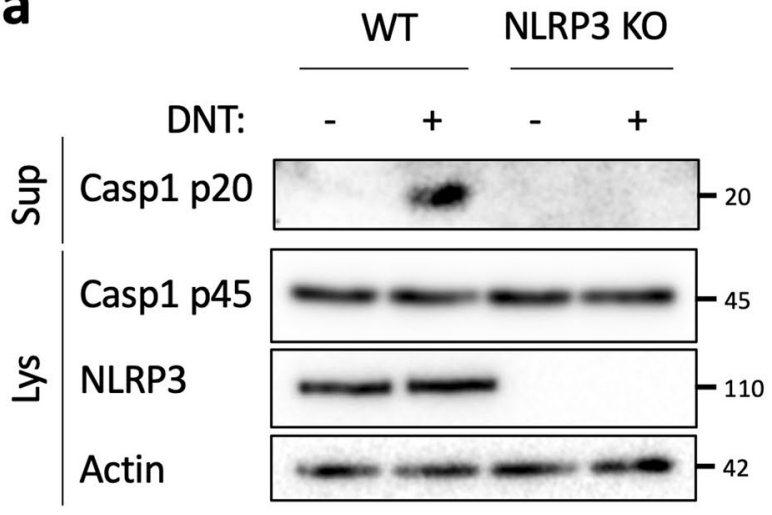

C

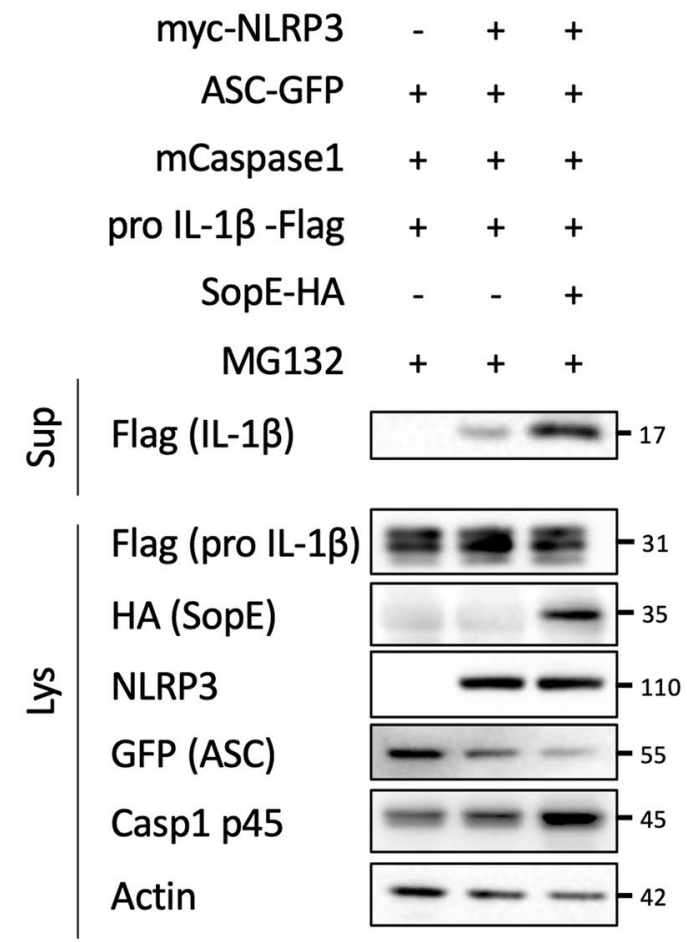

b

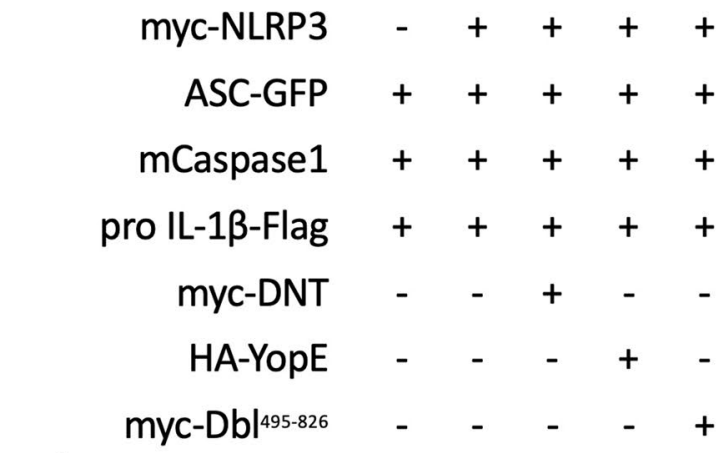

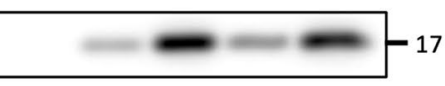

Flag (pro IL-1ß)

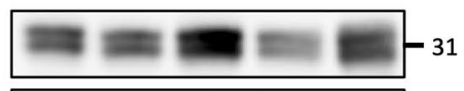

NLRP3

GFP (ASC)
Casp1 p45
myc (DNT)
HA (YopE)
myc (Dbl)
Actin

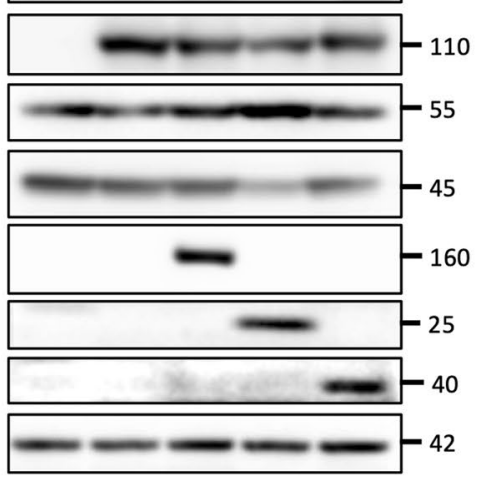

d

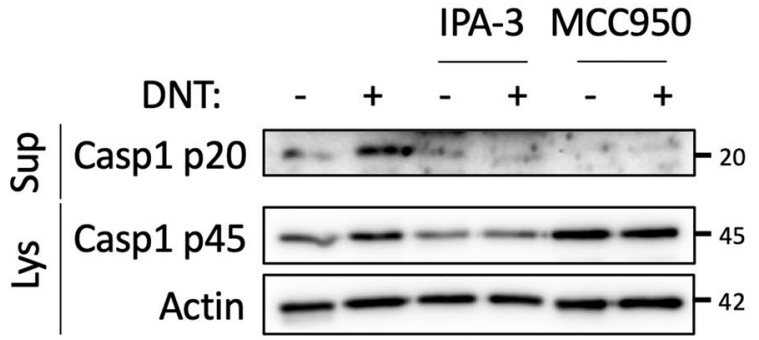

Extended Data Fig. 4 | Toxins mediated Rho GTPases activation but not inhibition trigger the NLRP3 inflammasome. a, BMDMs isolated from wild-type or NLRP3 knock out C57BL/6 J mice were treated with DNT $(1 \mu \mathrm{g} / \mathrm{mL})$ for $8 \mathrm{~h}$. Supernatants and cell lysates were analyzed by immunoblot. b-c, HEK293T cells were transfected as indicated with plasmids encoding NLRP3 inflammasome components (myc-NLRP3, ASC-GFP, mCaspase-1) and pro-IL-1 $\beta$-Flag together with (b) myc-DNT, HA-YopE or myc-Dbl ${ }^{495-826}$ or (c) transfected with SopE-HA and treated with MG132 to block SopE degradation $(10 \mu \mathrm{M})$. Supernatants and cell lysates were analyzed by immunoblot. d, BMDMs isolated from C57BL/6 J mice were treated with IPA-3 (5 $\mu$ M) or MCC950 $(1 \mu \mathrm{M})$ for $45 \mathrm{~min}$ prior to $8 \mathrm{~h}$ of DNT treatment $(1 \mu \mathrm{g} / \mathrm{mL})$. Supernatants and cell lysates were analyzed by immunoblot. The numbers on the side of the immunoblots indicate molecular weight $(\mathrm{kDa})$. Experiments were repeated at least three times, and representative data are shown. 
a

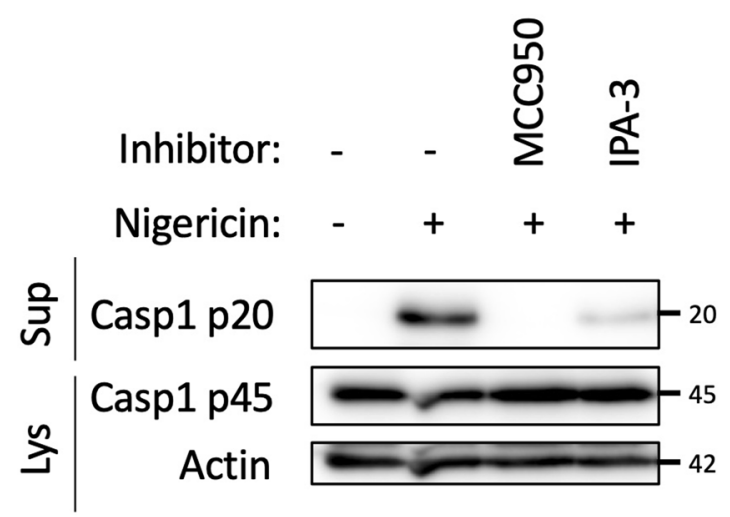

b

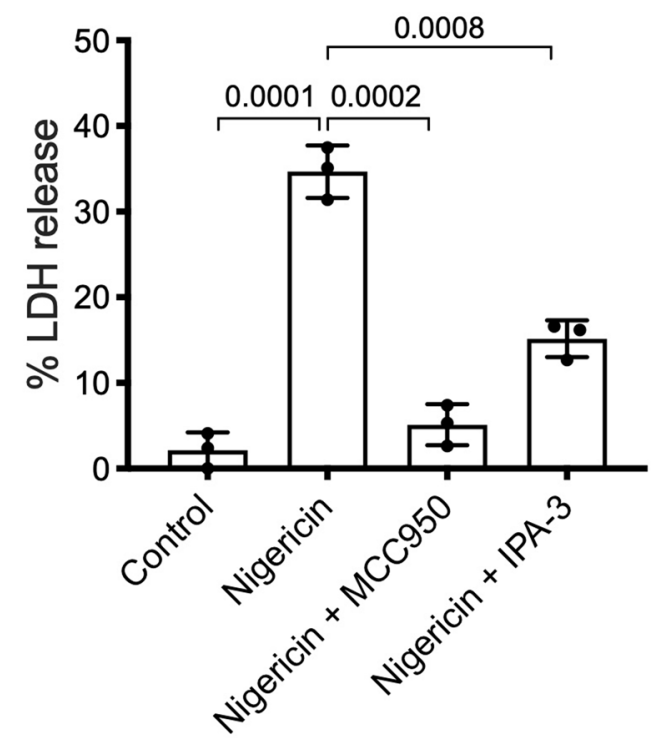

C

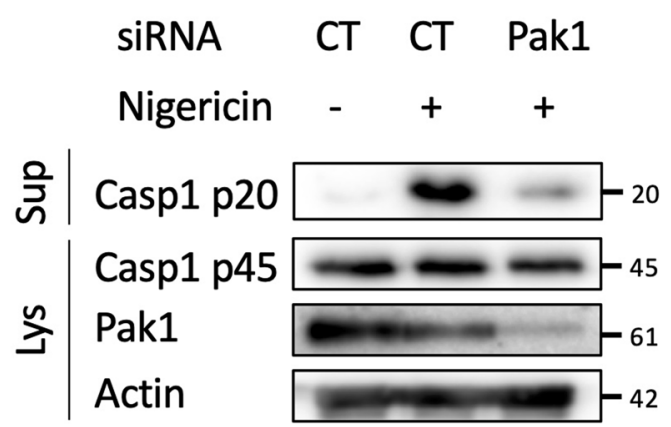

Extended Data Fig. 5 | Inhibition of Pak1 diminishes NLRP3 activation by Nigericin. a,b, BMDMs isolated from C57BL/6 J mice were treated with MCC950 $(1 \mu \mathrm{M})$ or IPA-3 $(5 \mu \mathrm{M})$ for 45 min prior to Nigericin $(5 \mu \mathrm{M})$ treatment for 30 min. Supernatants and cell lysates were analyzed by (a) immunoblot and (b) supernatants were analyzed for $L D H$ release $(n=3$ biologically independent experiments). Statistical analyses were performed using a two-tailed nonparametric Mann Whitney test. $n=3$ biologically independent samples were analyzed. c, BMDMs isolated from C57BL/6 J mice were treated for $72 \mathrm{~h}$ with non-targeting $(\mathrm{CT})$ or Pak1-targeting siRNA before treatment with Nigericin $(5 \mu \mathrm{M})$ for 30 min. Supernatants and cell lysates were analyzed by immunoblot. The numbers on the side of the immunoblots indicate molecular weight $(\mathrm{kDa})$. Experiments were repeated at least three times, and representative data are shown. Data are expressed as the mean \pm SEM. 


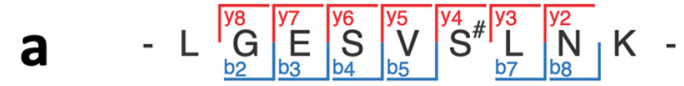

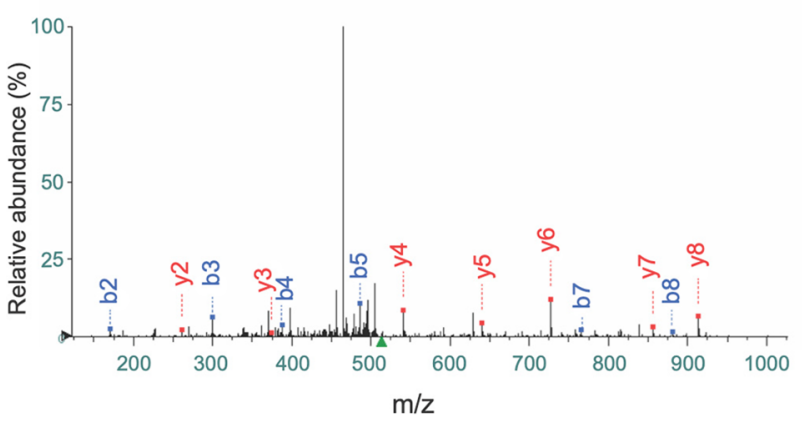

b
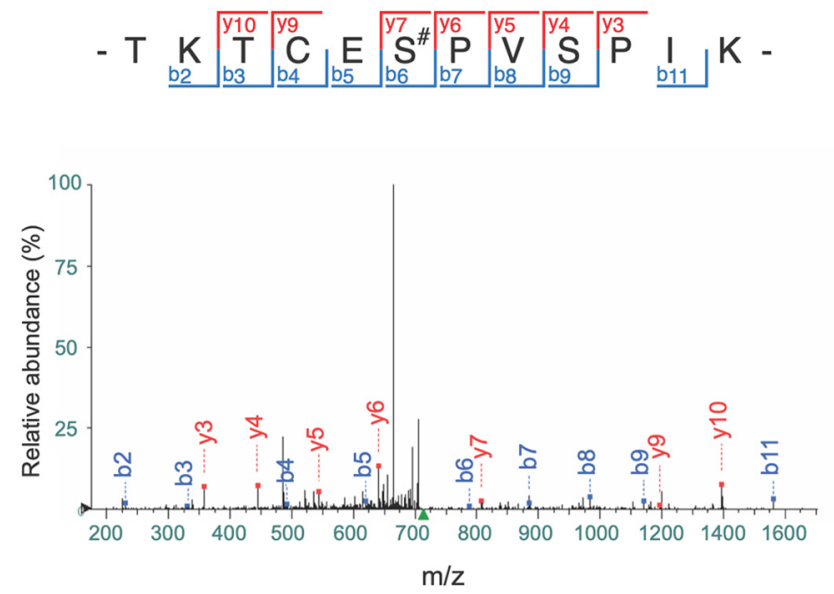

C
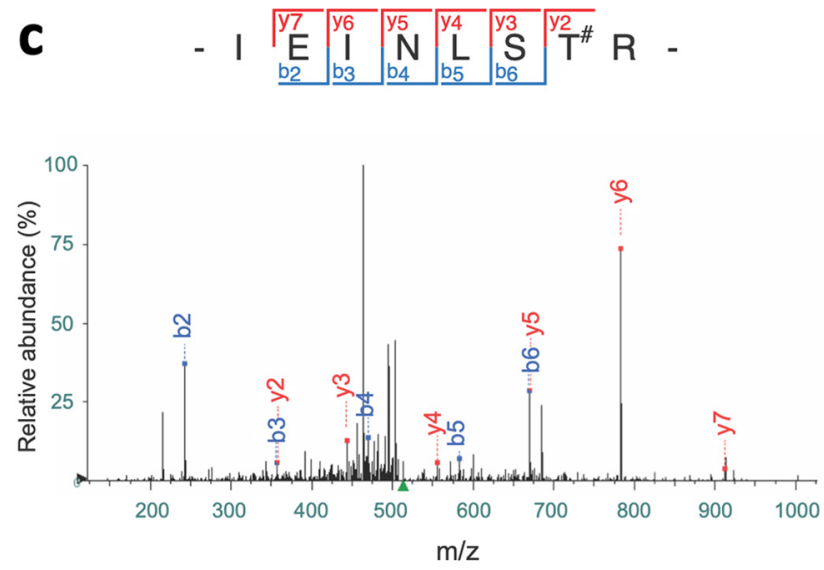

d

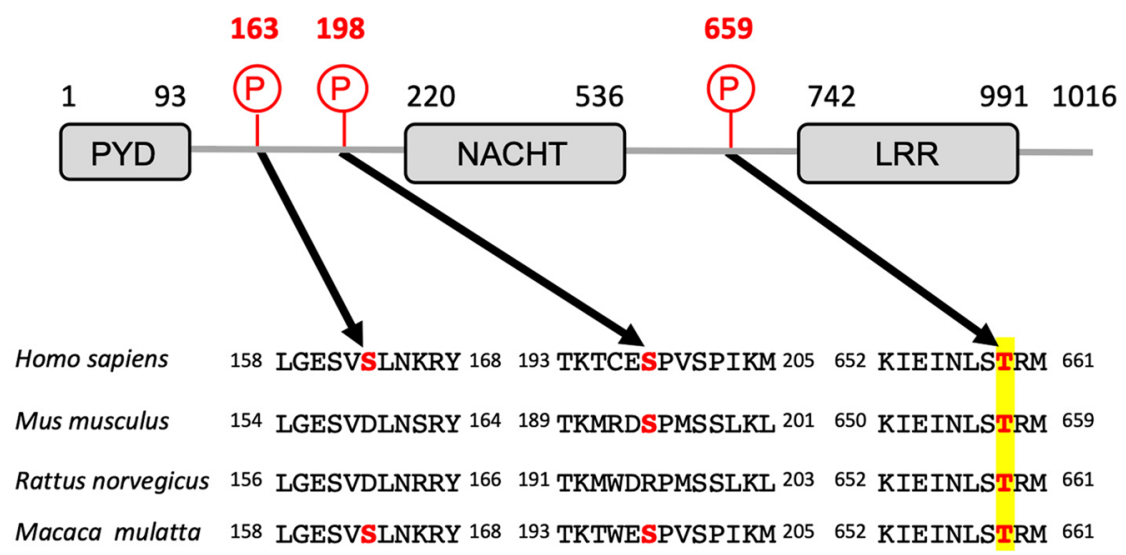

Extended Data Fig. 6 | Mass spectrometry analysis of Pak1 triggered NLRP3 phosphorylation. a-c, Fragmentation spectra of human NLRP3 peptides showing phosphorylation of Ser-163, Ser-198 and Thr-659. d, Representation of NLRP3 domain structure and sequence alignment of NLRP3 ortholog peptides surrounding phosphorylated residues identified by mass spectrometry. The phosphorylated residues are in bold red. 
a

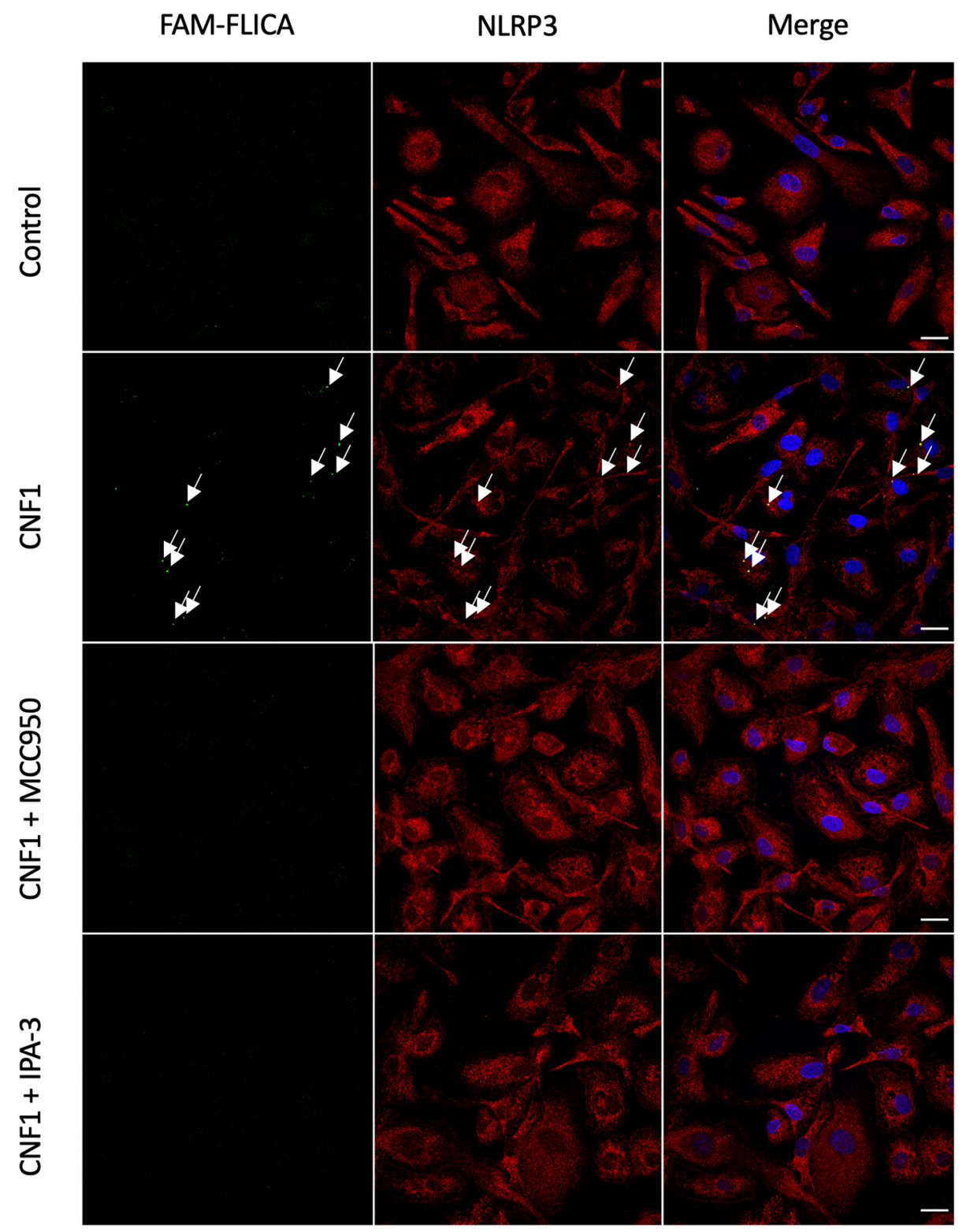

b

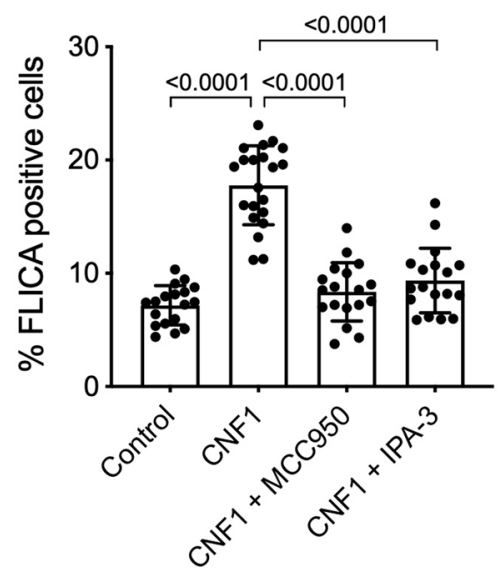

Extended Data Fig. 7 | See next page for caption. 
Extended Data Fig. 7 | Conservation of the Pak-NLRP3 axis in Human monocyte-derived macrophages. a-b, Human monocyte-derived macrophages (hMDMs) were pretreated with vehicle, MCC950 $(1 \mu \mathrm{M})$ or IPA-3 $(5 \mu \mathrm{M})$ for 45 min before CNF1 $(500 \mathrm{ng} / \mathrm{mL})$ treatment for $6 \mathrm{~h}$. Active Caspase-1 was stained with FAM-FLICA (green), NLRP3 (red) and nuclei (blue) were stained for immunofluorescence and confocal microscopy imaging. Arrows indicates FAM-FLICA dots that colocalize with NLRP3. Scale bar: $20 \mu \mathrm{m}$. b, quantification of FAM-FLICA positive cells. Data are expressed as the mean \pm SEM. Statistical analyses were performed using a two-tailed unpaired Student's t-test. Each dot represents 100 cells $(n=1800$ cells). Experiments were repeated at least three times, and representative data are shown. 


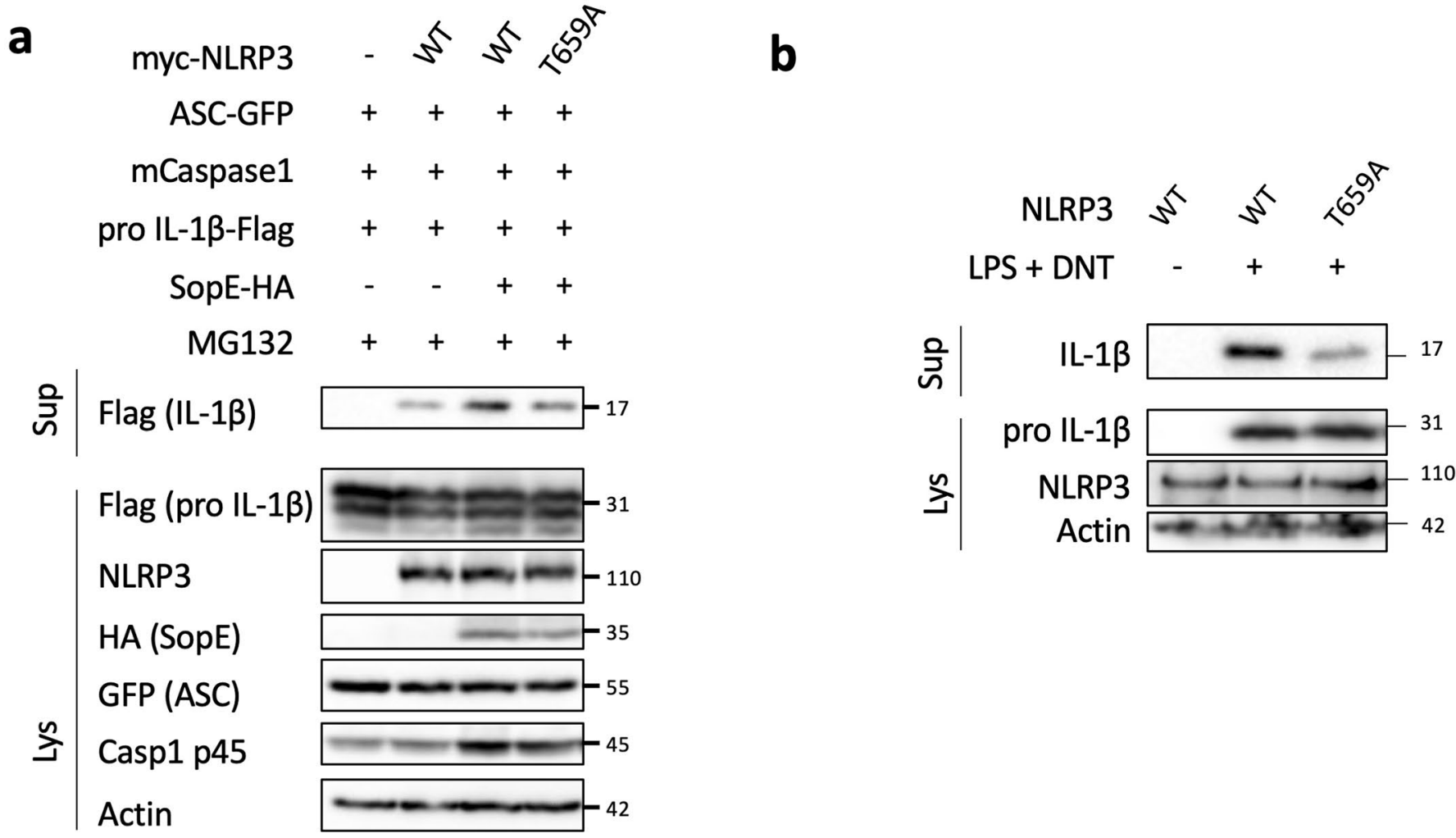

Extended Data Fig. 8 | The NLRP3 T659A mutant inhibit the IL-1 $\beta$ maturation triggered by SopE and DNT. a, HEK293T cells were transfected with plasmids encoding NLRP3 inflammasome components (ASC-GFP, mCaspase-1) and pro-IL-1 1 -Flag and either myc-NLRP3 (WT) or myc-NLRP3 T659A together with SopE-HA and treated with MG132 $(10 \mu \mathrm{M})$ to block SopE degradation. Supernatants and cell lysates were analyzed by immunoblot. b, NLRP3 knock-out iBMDMs reconstituted either with NLRP3 or NLRP3 T659A were treated with vehicle or LPS $(100 \mathrm{ng} / \mathrm{mL})$ and DNT $(1 \mu \mathrm{gg} / \mathrm{mL})$ for $8 \mathrm{~h}$. The numbers on the side of the immunoblots indicate molecular weight $(\mathrm{kDa})$. Experiments were repeated at least three times, and representative data are shown. 
a

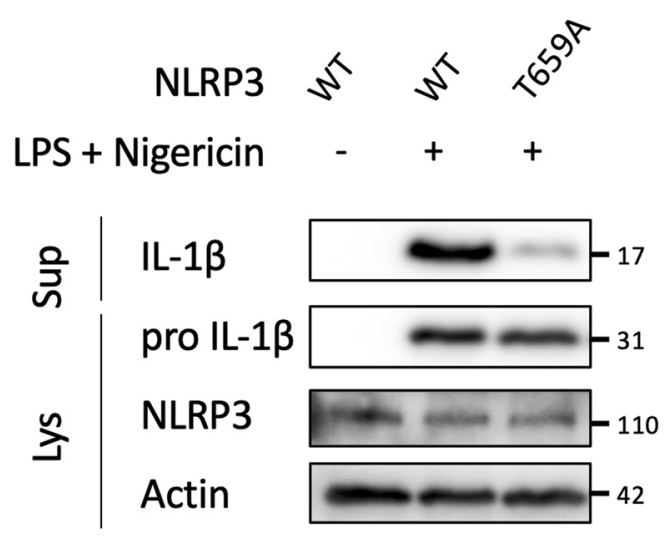

b

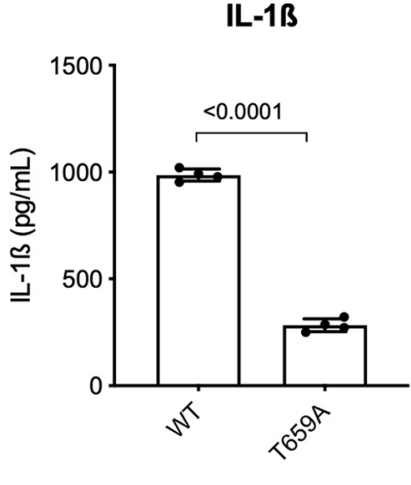

NLRP3
TNF- $\alpha$

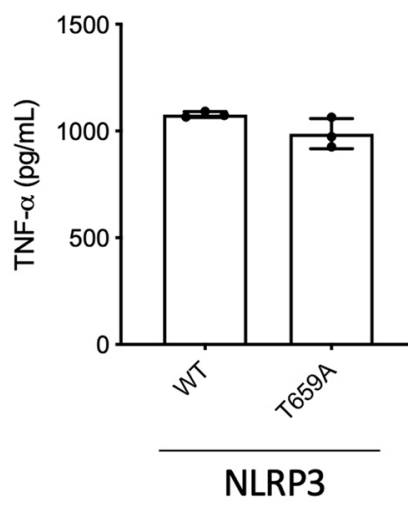

Extended Data Fig. 9 | Macrophages expressing the NLRP3 T659A mutant have an impaired Nigericin- triggered IL-1ß maturation. a-b, iBMDMs stably expressing either NLRP3 or NLRP3 T659A were treated with Nigericin $(5 \mu \mathrm{M})$ for $30 \mathrm{~min}$. Supernatants and cell lysates were analyzed by immunoblot and by ELISA for IL-1 $\beta(n=4$ biologically independent samples $)$ and TNF- $\alpha(n=3$ biologically independent samples $)$. Data are expressed as the mean \pm SEM. Statistical analyses were performed using a two-tailed unpaired Student's t-test. The numbers on the side of the immunoblots indicate molecular weight $(\mathrm{kDa})$. Experiments were repeated at least three times, and representative data are shown. 
a

\section{E. coli CNF1-}

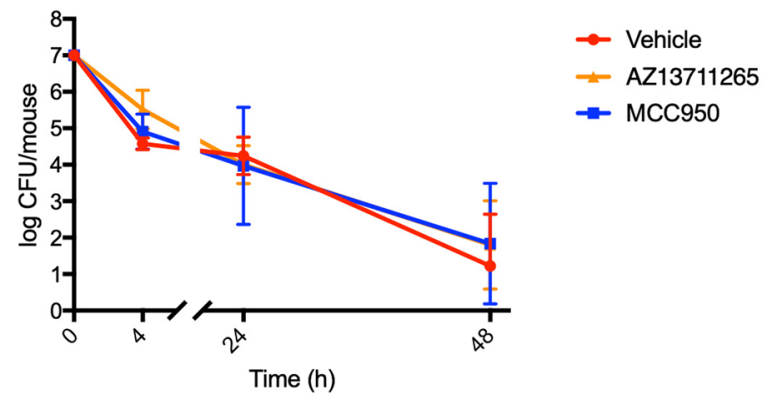

b

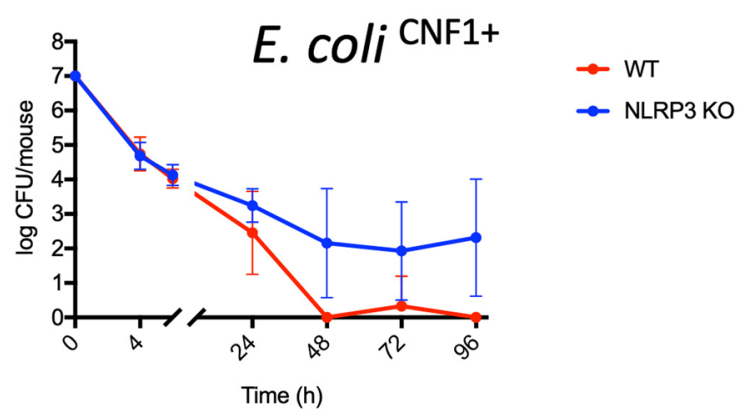

C

E. coli CNF1-

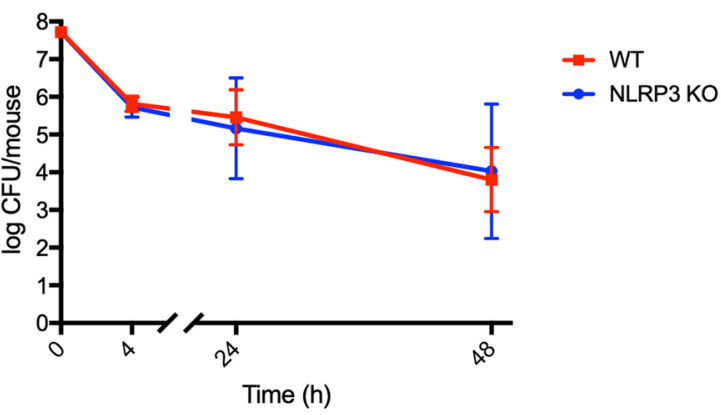

d

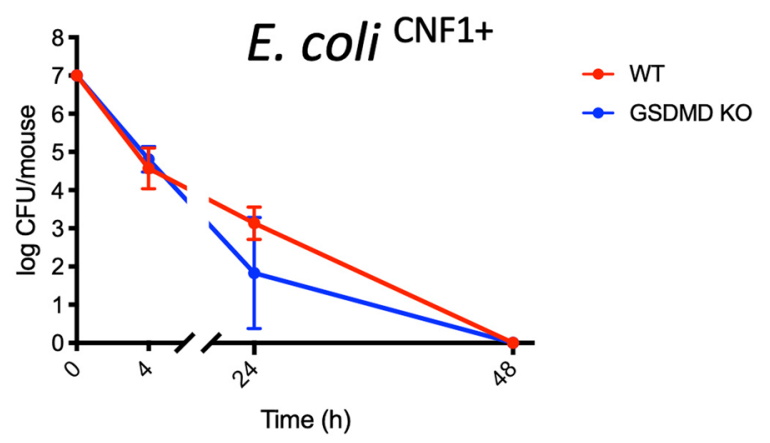

Extended Data Fig. 10 | See next page for caption. 
Extended Data Fig. $10 \mid$ E. coli ${ }^{\text {CNF1- }}$ clearing is not affected by Pak1 or NLRP3 inhibition and E. coli ${ }^{\text {CNF1+ }}$ clearing does not rely on GSDMD. a-d, Wild-type or knock-out mice were infected intravenously with isogenic CNF1-deleted $E$. coli (E. coli ${ }^{\mathrm{CNF} 1-}$ ) or CNF1 expressing E. coli (E. coli $\left.{ }^{\mathrm{CNF1+}}\right)$. a, Wild-type mice were injected intraperitoneally with $10 \mathrm{mg} / \mathrm{kg}$ AZ13711265 or $50 \mathrm{mg} / \mathrm{kg} \mathrm{MCC950} \mathrm{or} \mathrm{vehicle} \mathrm{once} \mathrm{a} \mathrm{day} \mathrm{and} \mathrm{were} \mathrm{infected} \mathrm{intravenously} \mathrm{with} \mathrm{isogenic}$ CNF1-deleted E. coli (E. coli ${ }^{\mathrm{CNF} 1-}$ ) prior to the collection of peripheral blood at $4 \mathrm{~h}, 24 \mathrm{~h}$ and $48 \mathrm{~h}$ for measurement of bacteraemia ( $\mathrm{n}=5 \mathrm{mice}$ per group). b. Wild-type or NLRP3 knock-out C57BL/6 J mice were infected intravenously with CNF1 expressing E. coli (E. coli ${ }^{\mathrm{CNF}+}$ ) prior to the collection of peripheral blood at $4 \mathrm{~h}, 24 \mathrm{~h}, 48 \mathrm{~h}, 72 \mathrm{~h}$ and $96 \mathrm{~h}$ for measurement of bacteraemia ( $\mathrm{n}=6$ per group). c, Wild-type ( $\mathrm{n}=6$ mice) or NLRP3 knock-out C57BL/6 J mice $\left(\mathrm{n}=4\right.$ mice) were infected intravenously with isogenic CNF1-deleted $E$. coli (E. coli $\left.{ }^{\mathrm{CNF} 1-}\right)$ prior to the collection of peripheral blood at $4 \mathrm{~h}, 24 \mathrm{~h}$ and $48 \mathrm{~h}$ for measurement of bacteraemia ( $n=6$ per group). d, Wild-type ( $n=6$ mice) or GSDMD knock-out C57BL/6J mice $(n=6$ mice) were infected intravenously with $\mathrm{E}$. coli ${ }^{\mathrm{CNF} 1+}$ prior to the collection of peripheral blood at $4 \mathrm{~h}, 24 \mathrm{~h}$ and $48 \mathrm{~h}$ for measurement of bacteraemia. Experiments were repeated two times and representative data are shown. Data are expressed as the geometric mean $\pm 95 \mathrm{Cl}$. 


\section{Reporting Summary}

Nature Research wishes to improve the reproducibility of the work that we publish. This form provides structure for consistency and transparency in reporting. For further information on Nature Research policies, see Authors \& Referees and the Editorial Policy Checklist.

\section{Statistics}

For all statistical analyses, confirm that the following items are present in the figure legend, table legend, main text, or Methods section.

n/a $\mid$ Confirmed

$\square$ \The exact sample size $(n)$ for each experimental group/condition, given as a discrete number and unit of measurement

$\square$ \ A statement on whether measurements were taken from distinct samples or whether the same sample was measured repeatedly

The statistical test(s) used AND whether they are one- or two-sided

$\square \bigotimes$ Only common tests should be described solely by name; describe more complex techniques in the Methods section.

$\bigotimes \square$ A description of all covariates tested

Х $\square$ A description of any assumptions or corrections, such as tests of normality and adjustment for multiple comparisons

A full description of the statistical parameters including central tendency (e.g. means) or other basic estimates (e.g. regression coefficient)

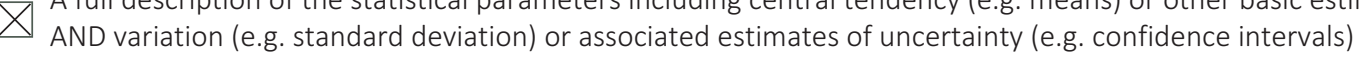

$\square$ For null hypothesis testing, the test statistic (e.g. $F, t, r$ ) with confidence intervals, effect sizes, degrees of freedom and $P$ value noted

$\square$ Give P values as exact values whenever suitable.

Х $\square$ For Bayesian analysis, information on the choice of priors and Markov chain Monte Carlo settings

Х $\square$ For hierarchical and complex designs, identification of the appropriate level for tests and full reporting of outcomes

Х $\square$ Estimates of effect sizes (e.g. Cohen's $d$, Pearson's $r$ ), indicating how they were calculated

Our web collection on statistics for biologists contains articles on many of the points above.

\section{Software and code}

Policy information about availability of computer code

Data collection Incucyte Zoom v6.2.9200.0 (Essen BioScience)

Data analysis Data were analyzed using GraphPad Prism software v8.2.1 and Fiji v2.1.0 by ImageJ and FlowJo v10.6.2

For manuscripts utilizing custom algorithms or software that are central to the research but not yet described in published literature, software must be made available to editors/reviewers. We strongly encourage code deposition in a community repository (e.g. GitHub). See the Nature Research guidelines for submitting code \& software for further information.

\section{Data}

Policy information about availability of data

All manuscripts must include a data availability statement. This statement should provide the following information, where applicable:

- Accession codes, unique identifiers, or web links for publicly available datasets

- A list of figures that have associated raw data

- A description of any restrictions on data availability

All data supporting the findings of this study are available within the article and its supplementary information or from the corresponding author upon reasonable request. Source data are provided with this paper.

\section{Field-specific reporting}

Please select the one below that is the best fit for your research. If you are not sure, read the appropriate sections before making your selection. \ Life sciences 


\section{Life sciences study design}

All studies must disclose on these points even when the disclosure is negative.

Sample size $\quad$ For experiments involving quantification, $n=3$ was chosen as the minimal replicate number, and sample size was determined by the number positive cells or samples within the replicates. We determined this to be sufficient owing to internal control (specific staining of known markers) and low observed variability between samples. For mice experiments, calculations were based on previous publication (Diabaté et al 2015; DOI: 10.1371/journal.ppat.1004732) and the G*Power software.

\section{Data exclusions No data were excluded}

\begin{tabular}{l|l} 
Replication & For all the data presented attempts were successful. The patterns of marker observed were consistent between experiments and with
\end{tabular} previously known results. Experiements were repeted at least three times and performed independently.

Randomization Field used for imaging were selected randomly by the microscope. All cells and puncta that passed quality control were analyzed equally.

Blinding Investigators were blinded for in vivo experiments and RNAi screen experiments. For other experiments, the investigators were blinded to group allocation during data collection.

\section{Reporting for specific materials, systems and methods}

We require information from authors about some types of materials, experimental systems and methods used in many studies. Here, indicate whether each material, system or method listed is relevant to your study. If you are not sure if a list item applies to your research, read the appropriate section before selecting a response.

\begin{tabular}{l|l} 
Materials \& experimental syste \\
\hline $\mathrm{n} / \mathrm{a}$ & Involved in the study \\
\hline & $\bigotimes$ Antibodies \\
$\square$ & $\square$ Eukaryotic cell lines \\
$\square$ & $\square$ Animals and other organisms \\
$\square$ & $\square$ Human research participants \\
$\square$ & $\square$ Clinical data
\end{tabular}

\begin{tabular}{l} 
Methods \\
\hline n/a \\
$\square$ \\
$\square$ Involved in the study \\
$\square$ ChIP-seq \\
$\square$ Flow cytometry \\
$\square$ MRI-based neuroimaging
\end{tabular}

\section{Antibodies}

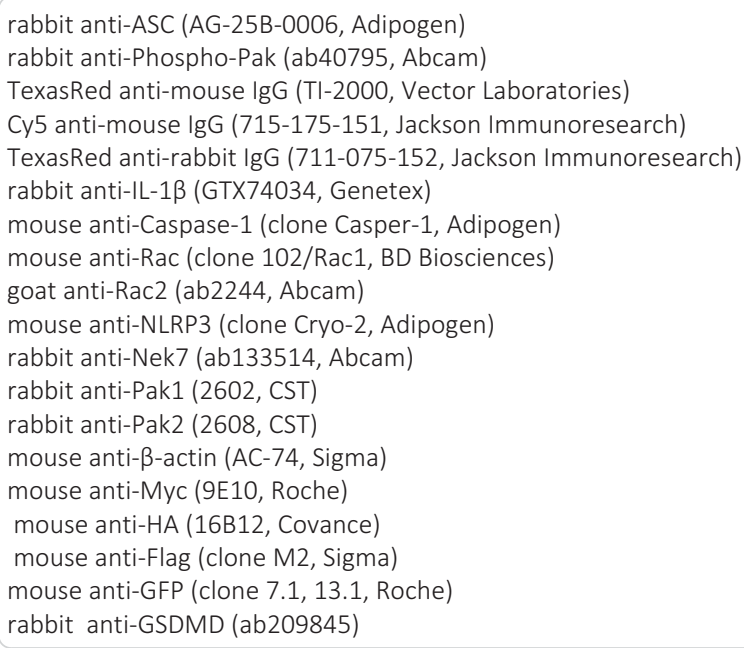

Antibodies were all validated by the manufacturer. Primary antibodies directed against ASC, Pak1, Pak2, Caspase-1, Rac, Rac2, NLRP3, Nek7, GSDMD were validated in this study or in our previous publication (Diabaté et al 2015; DOI: 10.1371/ journal.ppat.1004732) by westen-blot using either cells lysated collected from transfected by the corresponding siRNA or from the corresponding knock-out macrophages. 
Policy information about cell lines

Cell line source(s)

HEK293T, Immortalized BMDM

Authentication

All cell lines were authenticated by using PCR with species specific primers

Mycoplasma contamination

Commonly misidentified lines

(See ICLAC register)

Cells were tested negative for mycoplasma contamination

No commonly misidentified cell lines were used

\section{Animals and other organisms}

Policy information about studies involving animals; ARRIVE guidelines recommended for reporting animal research

Laboratory animals

$\mathrm{BALB} / \mathrm{c}$ mice

C57BL/6J mice

C57BL/6J NLRP3 KO mice

C57BL/6J Pak1 KO mice

C57BL/6J GSDMD KO mice

C57BL/6J ASC-citrine mice

7 weeks-old mice were housed with their littermates and kept on a regular 12 -h light/dark cycle, room temperature: $20-25^{\circ} \mathrm{C}$; relative humidity: 50-70\%. Food and water were available ad libitum.

Wild animals

the study did not involved wild animals

Field-collected samples

the study did not involved sample collected from the field

Ethics oversight

This study was carried out in strict accordance with the guidelines of the Council of the European Union

(Directive 86/609/EEC) regarding the protection of animals used for experimental and other scientific

purposes. The protocol was approved by the Institutional Animal Care and Use Committee on the Ethics

of Animal Experiments of Nice, France (reference: APAFIS\#18322-20181218099427035 v2).

Note that full information on the approval of the study protocol must also be provided in the manuscript.

\section{Flow Cytometry}

Plots

Confirm that:

\The axis labels state the marker and fluorochrome used (e.g. CD4-FITC).

\The axis scales are clearly visible. Include numbers along axes only for bottom left plot of group (a 'group' is an analysis of identical markers).

\All plots are contour plots with outliers or pseudocolor plots.

$\bigotimes$ A numerical value for number of cells or percentage (with statistics) is provided.

\section{Methodology}

Sample preparation

BMDM isolated from C57BL/6J mice constitutively expressing ASC-citrine fusion protein (R26-CAG-ASC-citrine) were treated with LPS $(100 \mathrm{ng} / \mathrm{mL})$ for $16 \mathrm{~h}$ before $6 \mathrm{~h}$ of treatment with vehicle or CNF1 $(500 \mathrm{ng} / \mathrm{mL})$ or $30 \mathrm{~min}$ with Nigericin $(5 \mu \mathrm{M})$. Cells were collected and analyzed by flow cytometry.

Instrument

Flow cytometry data were collected using the the BD FACSCanto II

Software

Flow cytometry data were analyzed using FlowJo v10.6.2

Cell population abundance

For each sample, at least 10000 ASC-citrine expressing cells were analyzed

Gating strategy

Doublets were excluded using SSC-A (area) and SSC-H (height) plot, cells with a high expression of ASC-citrine were gated and then analyzed for ASC-citrine signal area (ASC-citrine-A) and ASC-citrine signal height (ASC-citrine-H). Cells with ASC specks were defined with a higher ASC-H:ASC-A ratio.

\Tick this box to confirm that a figure exemplifying the gating strategy is provided in the Supplementary Information. 